\title{
In Search of Spectroscopic Signatures of Periodontitis: A SERS-Based Magnetomicrofluidic Sensor for Detection of Porphyromonas gingivalis and Aggregatibacter actinomycetemcomitans
}

\author{
Evelin Witkowska,* Anna M. Łasica, ${ }^{\perp}$ Krzysztof Niciński, ${ }^{\perp}$ Jan Potempa, and Agnieszka Kamińska*
}

Cite This: ACS Sens. 2021, 6, 1621-1635

Read Online

ACCESS | Lill Metrics \& More | 回 Article Recommendations ｜ＳＳ Supporting Information

ABSTRACT: Recently, Porphyromonas gingivalis, the keystone pathogen implicated in the development of gum disease (periodontitis), was detected in the brains of Alzheimer's disease patients, opening up a fascinating possibility that it is also involved in the pathobiology of this neurodegenerative illness. To verify this hypothesis, an unbiased, specific, and sensitive method to detect this pathogen in biological specimens is needed. To this end, our interdisciplinary studies demonstrate that $P$. gingivalis can be easily identified by surface-enhanced Raman scattering (SERS). Moreover, based on SERS measurements, $P$. gingivalis can be distinguished from another common periodontal pathogen, Aggregatibacter actinomycetemcomitans, and

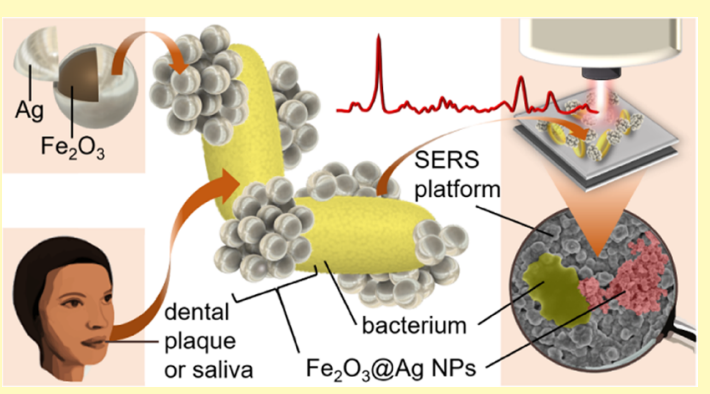
also from ubiquitous oral Streptococcus spp. The results were confirmed by principal component analysis (PCA). Furthermore, we have shown that different $P$. gingivalis and A. actinomycetemcomitans strains can easily adsorb to silver-coated magnetic nanoparticles $\left(\mathrm{Fe}_{2} \mathrm{O}_{3} @ \mathrm{AgNPs}\right)$. Thus, it is possible to magnetically separate investigated bacteria from other components of a specimen using the microfluidic chip. To obtain additional enhancement of the Raman signal, the NPs adsorbed to bacterial cells were magnetically attracted to the Si/Ag SERS platform. Afterward, the SERS spectra could be recorded. Such a time-saving procedure can be very helpful in rapid medical diagnostics and thus in starting the appropriate pharmacological therapy to prevent the development of periodontitis and associated comorbidities, e.g., Alzheimer's disease.

KEYWORDS: surface-enhanced Raman spectroscopy (SERS), principal component analysis (PCA), Porphyromonas gingivalis, Aggregatibacter actinomycetemcomitans, silver-coated magnetic nanoparticles ( $\left.\mathrm{Fe}_{2} \mathrm{O}_{3} @ A g N P s\right)$, periodontitis, Alzheimer's disease

$S^{4}$ urface-enhanced Raman spectroscopy (SERS) is a technique allowing us to obtain strong amplification of the Raman scattering effect on analyzed molecules, which are localized in "hot spots", the crevices of the metal nanostructures characterized by very strong local field enhancement caused by the surface plasmon resonance. ${ }^{1,2}$ The mentioned nanostructures are usually made of SERS-active metals, such as silver, gold, copper, or their alloys. ${ }^{3}$ The reason for using these metals specifically is associated with the fact that they have localized surface plasmon resonance (LSPR) that covers most of the visible and near-infrared wavelength ranges. This, in turn, means that they are suitable for use with visible and NIR laser systems commonly applied in Raman measurements.

The SERS technique is also known for its high level of sensitivity and specificity, which allows for the detection, identification, and characterization of various chemical compounds or biological materials. As a result, one may obtain a specific and unique fingerprint of the compound/ material under study. The SERS effect relies on the combination of two mechanisms, electromagnetic (EM) $)^{5,6}$ and chemical (charge-transfer, CT), ${ }^{7,8}$ that can together lead to the amplification of the Raman signal even by 12 orders of magnitude in comparison to normal Raman spectroscopy. ${ }^{9}$
Such enhancement of inherently weak Raman bands allows us to characterize single molecules ${ }^{10}$ or detect and identify the samples of biological origin. ${ }^{11}$

Huge sensitivity, high selectivity, and the possibility to perform rapid, label-free, and nondestructive analysis lead to a wide range of practical applications of the SERS technique. Currently, the technique is used in biomedical, analytical, and environmental studies, as well as in forensic science and the food industry. Recent progress in the field of preparation of SERS substrates ${ }^{12,13}$ has led to a large array of ready-to-use and commercially available products for a variety of applications. New approaches allowed also for the cost reduction of SERS platform preparation. Additionally, high-tech Raman spectrometers equipped with various laser lines have become more accessible due to substantial miniaturization and lower

Received: January 26, 2021

Accepted: March 19, 2021

Published: April 1, 2021 
purchase costs while maintaining high measurement parameters.

As a result, the interest in SERS detection and identification of biological samples such as proteins, viruses, fungal cells, and cancer cells has increased significantly. ${ }^{14-19}$ Moreover, numerous scientific publications have proven that SERS can be applied for reliable identification and detection of various bacterial strains. ${ }^{20-25}$ This is an important issue, especially when considering bacterial pathogens responsible for different human diseases.

In this work, we focused on Porphyromonas gingivalis, a Gram-negative, anaerobic bacterium found in the human oral cavity and responsible for chronic periodontitis. ${ }^{26,27} \mathrm{We}$ compared the obtained results for $P$. gingivalis with the spectra of Aggregatibacter actinomycetemcomitans and two streptococcal species. Of note, A. actinomycetemcomitans is recognized as the causative agent of a rare form of gum disease, aggressive periodontitis. Chronic periodontitis is a complex disorder resulting from dynamic interactions between pathogens, other oral microbiota, and the host immune system and is the second most prevalent oral disease, right after dental caries. Genetic, environmental, and behavioral factors such as immunodeficiencies, diabetes, poor oral hygiene, and cigarette smoking, to name a few, are also important for the course of the disease. Infection-driven inflammation leads to swollen and bleeding gums, degradation of periodontal ligament, resorption of alveolar bone, periodontal pocket formation, and eventually to teeth loss. ${ }^{28,29}$

Chronic periodontitis is a slowly developing pathology, not easy to diagnose, and is challenging to treat. Although it brings discomfort, pain, chewing difficulties, and eventually teeth exfoliation (if not treated), it is also associated with some serious systemic diseases such as rheumatoid arthritis, atherosclerosis, aspiration pneumonia, or preterm birth. ${ }^{30,31}$ Moreover, the periodontal pathogens are implicated in the development of cancer, ${ }^{32}$ and, recently, $P$. gingivalis was directly implicated as a putative contributor to the pathogenesis of Alzheimer's disease. It was shown that $P$. gingivalis virulence factors, gingipains, were present in patients' brains. ${ }^{33}$ Additionally, the bacterial colonization of the brain and the cerebrospinal fluid was detected through the polymerase chain reaction (PCR) technique. ${ }^{3333}$

Herein, we report an independent culturing method allowing for fast, specific, and sensitive detection of $P$. gingivalis, A. actinomycetemcomitans, and Streptococcus spp. We demonstrated that it is possible to obtain the intense and unique SERS spectra of investigated bacterial cells. Moreover, the principal component analysis (PCA) allowed us to separate the SERS spectra of bacteria belonging to different species (from 82 to $91 \%$ accuracy, depending on the type of the analyzed sample). Importantly, unique SERS spectra were clearly observed for different strains of $P$. gingivalis and $A$. actinomycetemcomitans, thus making it possible to distinguish one strain from another.

We also proved that the SERS method coupled with the microfluidic technique and magnetic separation allows us to detect and identify $P$. gingivalis and A. actinomycetemcomitans strains in liquid samples such as human saliva. For this purpose, the bacterial cells were mixed with $\mathrm{Fe}_{2} \mathrm{O}_{3} @ \mathrm{Ag}$ magnetic nanoparticles (NPs) in a microfluidic chip. The created bacteria-NP aggregates were next attracted by a neodymium magnet placed under the $\mathrm{Si} / \mathrm{Ag}$ platform. Owing to the use of both silver-coated NPs and a Si/Ag substrate, the greatly enhanced SERS signal, characteristic for each of the investigated bacterial species/strains, was obtained. The conducted experiments and results are the first step on the path to developing the method, which could be applied for reliable assessment of microbiological risks underlying the development of periodontitis and associated systemic comorbidities, such as rheumatoid arthritis and Alzheimer's disease.

\section{EXPERIMENTAL SECTION}

Bacterial Strains. Five strains of $P$. gingivalis [33277 (wt), W83 (wt), $\Delta \mathrm{K} / \triangle \mathrm{RAB}-\mathrm{A}, \Delta$ PorN, AL022] were obtained from the Institute of Microbiology, Faculty of Biology, University of Warsaw, Poland. The construction of $P$. gingivalis-mutated strains $(\Delta \mathrm{K} / \Delta \mathrm{RAB}-\mathrm{A}$, $\Delta$ PorN) was reported in the publication of Maria Rapala-Kozik et al., ${ }^{34}$ whereas generation of AL022 is described in the Supporting Information (Figure S1). Three strains of A. actinomycetemcomitans [HK1651 (wt), JP2, 652 (wt)] were a kind gift from Prof. Donald R. Demuth (University of Louisville School of Dentistry, Louisville, Kentucky, United States), while two streptococcal strains, namely, Streptococcus pseudopneumoniae 6178/12 and Streptococcus mitis 3705/ 04, were donated by Prof. Anna Skoczyńska (the National Reference Centre for Bacterial Meningitis in the National Medicines Institute, Warsaw, Poland). Relevant genotype/phenotype or origin information of all used strains is given in Table 1.

Table 1. Genotype and Phenotype Information of All Strains Used in the Study

\begin{tabular}{|c|c|c|}
\hline strain & relevant genotype/phenotype/origin & source \\
\hline \multicolumn{3}{|l|}{$P$. gingivalis } \\
\hline ATCC 33277 & wild type & 35 \\
\hline $\begin{array}{l}\text { W83 (ATCC } \\
\text { BAA-308) }\end{array}$ & $\begin{array}{l}\text { wild type; altered in fimbriae } \\
\text { production }\end{array}$ & 36 \\
\hline$\Delta \mathrm{K} / \Delta \mathrm{RAB}-\mathrm{A}$ & $\begin{array}{l}\text { W83: } k g p, r g p A, r g p B \\
\left(\operatorname{Tet}^{r} \mathrm{Cm}^{r} \mathrm{Em}^{\mathrm{r}}\right) ; \operatorname{devoid} \text { of all } \\
\text { gingipains }\end{array}$ & 34 \\
\hline$\Delta$ PorN & $\begin{array}{l}\text { W83: porN }\left(\mathrm{Em}^{\mathrm{r}}\right) \text {; defective in } \\
\text { T9SS (type IX secretion system) }\end{array}$ & 37 \\
\hline AL022 & $\begin{array}{l}\text { ATCC 33277: } \triangle P G N \_1642\left(\mathrm{Em}^{\mathrm{r}}\right) \\
\text { gene of unknown function }\end{array}$ & $\begin{array}{r}\text { present } \\
\text { study }\end{array}$ \\
\hline \multicolumn{3}{|l|}{ A. actinomycetemcomitans } \\
\hline HK 1651 & $\begin{array}{l}\text { wild type; serotype b, highly } \\
\text { leukotoxic, rough colony }\end{array}$ & 38 \\
\hline JP2 & $\begin{array}{l}\text { wild type; serotype b, smooth } \\
\text { colony, highly leukotoxic } \\
\text { derivative of HK1651 }\end{array}$ & 38,39 \\
\hline 652 & $\begin{array}{l}\text { wild type; serotype c, minimally } \\
\text { leukotoxic }\end{array}$ & 39 \\
\hline \multicolumn{3}{|l|}{ Streptococcus spp. } \\
\hline $\begin{array}{l}\text { S. } \\
\text { pseudopneumoniae } \\
6178 / 12\end{array}$ & human bronchial secretion & 40 \\
\hline S. mitis 3705/04 & human sputum & 40 \\
\hline
\end{tabular}

$P$. gingivalis. In the present study, two sets of $P$. gingivalis strains were used. (1) the W83 wild-type strain and its two derivatives, mutants with altered virulence, namely, $\triangle K / \triangle R A B-A(\triangle \mathrm{kgp} / \mathrm{rgp} A$ / $\operatorname{rgpB}$ ) and $\Delta$ porN. (2) The ATCC 33277 wild-type strain and its mutated progeny AL022 ( $\left.\triangle P G N \_1642\right)$ of an unknown phenotype.

The main difference between W83 and ATCC 33277 wild-type strains is that W83 is coated with a polysaccharide capsule and devoid of functional fimbriae. ${ }^{41}$ Similar features may be expected for $\Delta K /$ $\triangle R A B-A$ and $\triangle p o r N$ as they both show changes in the cell surface structure displayed by the greatly reduced and entirely absent electron-dense surface layer, respectively. ${ }^{42,43}$ The first phenotype is due to the lack of gingipains (Kgp, RgpA, and RgpB), the main virulence factors usually attached to the cell surface. The second phenotype is caused by the deficiency in T9SS, a secretion system 
(a)

(b)

(c)

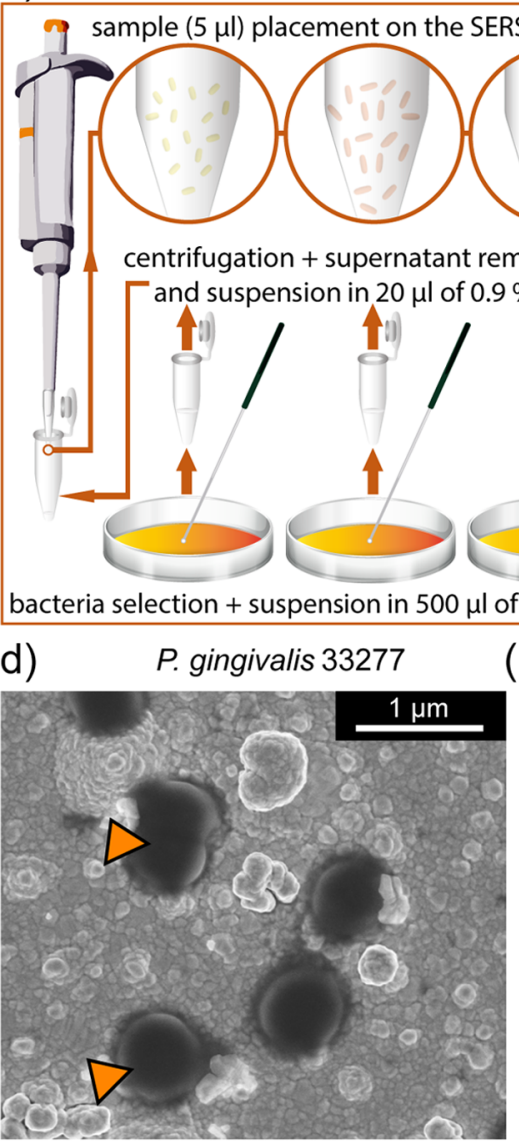

(b)

substrate

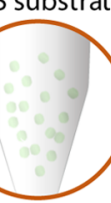

bacteria

Ag layer deposited via PVD
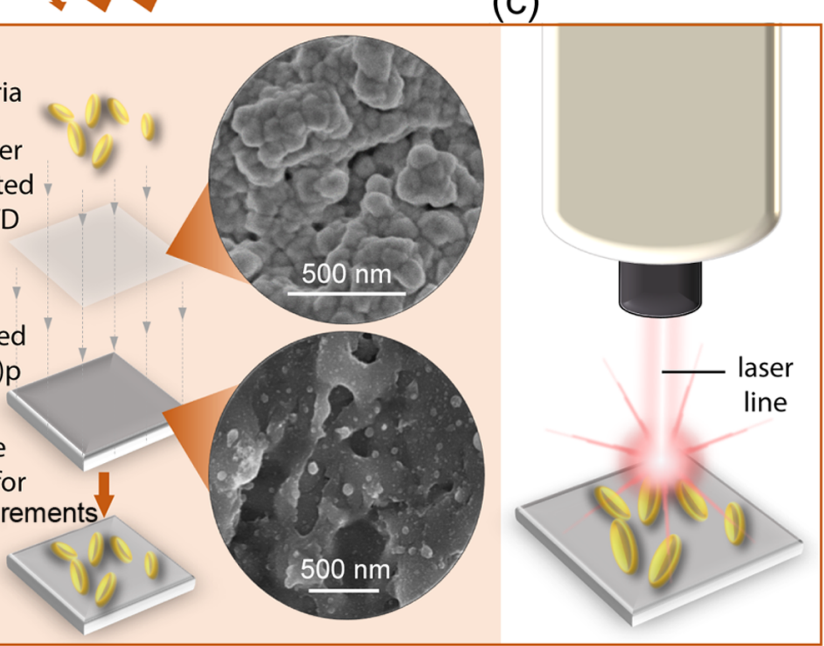

(d)

(e) A. actinomycetemcomitans HK165

(f) S. mitis 3705/04
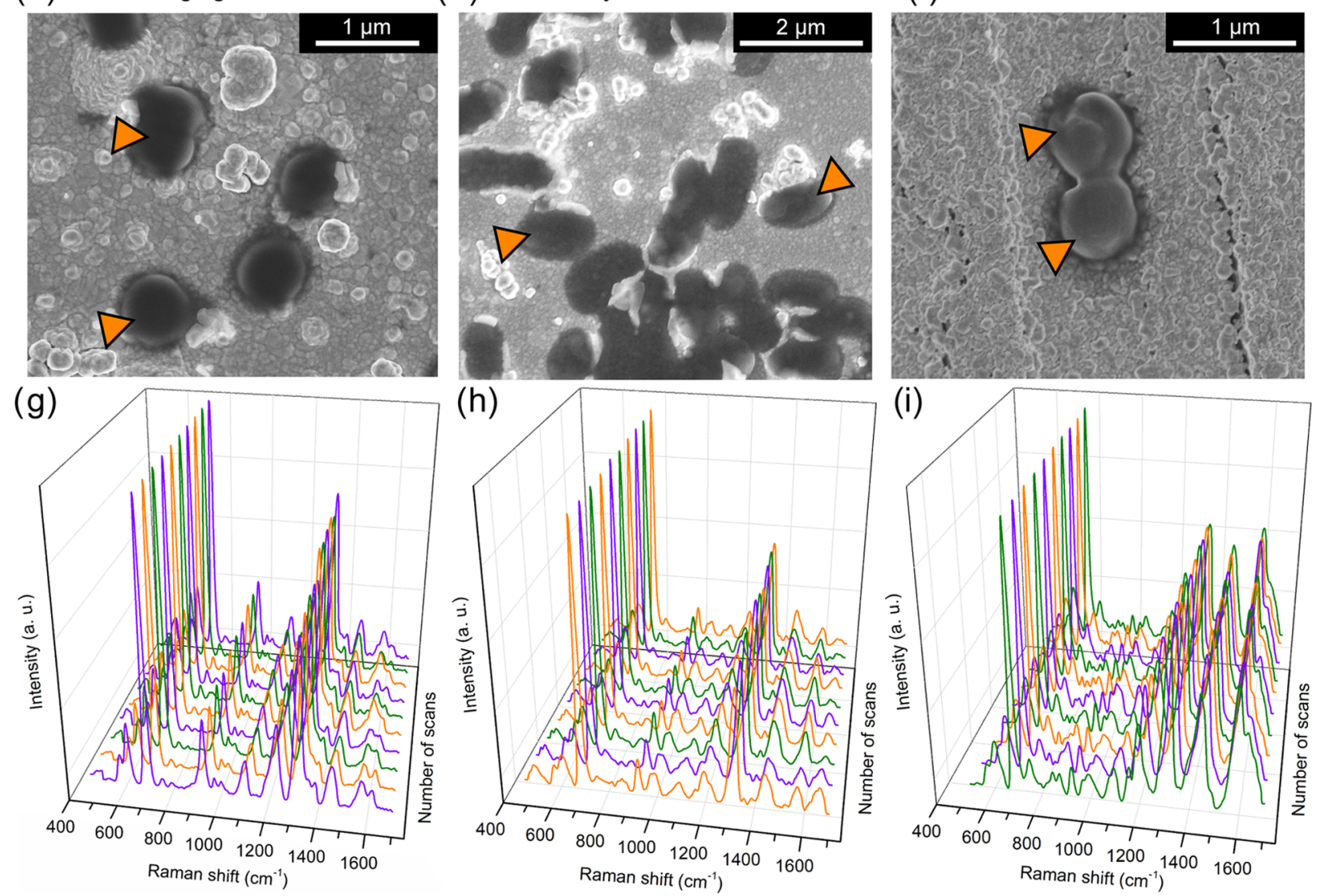

Figure 1. Preparation of the sample for SERS experiments, SEM imaging, and reproducibility of the SERS spectra. The experiment comprised preparation of bacterial cell samples (a), preparation of the Si/Ag SERS substrate (b), and SERS measurement of bacterial cells (c). (d-f) SEM images of three selected bacterial strains placed over the Si/Ag SERS platforms. (g-i) 3D plots showing the reproducibility of the SERS measurements performed for three selected bacterial strains. Orange arrowheads in all SEM images (d-f) indicate bacterial cells adsorbed to the $\mathrm{Si} /$ Ag platform.

transporting various proteins, including gingipains, across the membranes and subsequently attaching them to the cell surface. ${ }^{44}$

A. actinomycetemcomitans. The three A. actinomycetemcomitans strains analyzed in the present work are representatives of two serotypes: b, highly leukotoxic (strains HK1651 and JP2) and c, minimally leukotoxic (strain 652). Additionally, within serotype b, the strains HK1651 and JP2 show surface structure differences described as rough and smooth colonies, respectively. This is due to a spontaneous mutational event within the fimbria biogenesis operon. $^{38,39}$

Streptococci. In the present study, two different streptococcal species were used: S. mitis 3705/04, which inhabits the human mouth, and S. pseudopneumoniae 6178/12, which is the causative agent of pneumonia in humans and can also be found in the human oral cavity.

Culture Media and Growth Conditions of Bacterial Strains. P. gingivalis strains were grown in enriched BD BBL trypticase soy 
broth (eTSB per liter: $30 \mathrm{~g}$ of trypticase soy broth, $5 \mathrm{~g}$ of yeast extract,

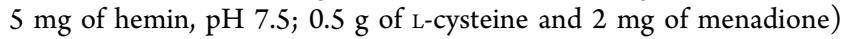
and on eTSB blood agar (eTSB medium containing 1.5\% agar and 5\% defibrinated sheep blood) at $37{ }^{\circ} \mathrm{C}$ in anaerobic conditions using an Anoxomat Mark II system (90\% nitrogen, 5\% carbon dioxide, and 5\% hydrogen). Cultures of mutated strains were additionally supplemented with appropriate antibiotics (erythromycin at $5 \mu \mathrm{g} / \mathrm{mL}$ and/ or tetracycline at $1 \mu \mathrm{g} / \mathrm{mL}$ and chloramphenicol at $3.5 \mu \mathrm{g} / \mathrm{mL}$ ).

A. actinomycetemcomitans strains were grown in $\mathrm{BD} \mathrm{BBL}$ brain heart infusion (BHI) broth and on BHI agar (1.5\% agar), both supplemented with $40 \mathrm{mg} / \mathrm{L} \mathrm{NaHCO}_{3}$, at $37{ }^{\circ} \mathrm{C}$ in microaerobic conditions using an Anoxomat Mark II system $\left(85 \% \mathrm{~N}_{2}, 10 \% \mathrm{CO}_{2}\right.$, $5 \% \mathrm{O}_{2}$ ), while streptococcal strains were cultured on Columbia blood agar at $37{ }^{\circ} \mathrm{C}$ in aerobic conditions.

All bacteria were grown to the early stationary phase (ca. $24 \mathrm{~h}$ in broth or $48 \mathrm{~h}$ on plates in the case of $P$. gingivalis and $A$. actinomycetemcomitans or ca. $16 \mathrm{~h}$ on plates in the case of $S$. pseudopneumoniae and S. mitis).

The bacterial strains belonging to $P$. gingivalis and $A$. actinomycetemcomitans were cultured both on solid (agar) and in a liquid medium to check if the culture conditions are altered for the SERS measurements.

Human Saliva. The human saliva used in the experiments was obtained from a healthy male volunteer. Before experiments, the saliva was placed in the syringe and filtered by applying syringe filters with pore sizes of $0.2 \mu \mathrm{m}$. The performance of experiments was in accordance with the institutional guidelines and relevant laws and was approved by the Ethics and Bioethics Committee of Cardinal Stefan Wyszyński University in Warsaw.

Sample Preparation for SERS Measurements. In the case of bacteria cultured on solid (agar) media, about three single bacterial colonies were selected and suspended in $500 \mu \mathrm{L}$ of a sterile saline solution $(0.9 \% \mathrm{NaCl})$ via an inoculation loop. Then, bacteria were gently mixed with the saline solution by an automatic pipette. In the case of bacteria grown in liquid media, $500 \mu \mathrm{L}$ of each culture was placed in a $1.5 \mathrm{~mL}$ tube. Next, both types of samples were centrifuged ( $5 \mathrm{~min}, 1070 \mathrm{~g}$ ), the supernatants were discarded, and the pellets were suspended in $500 \mu \mathrm{L}$ of the sterile saline solution. The washing procedure was repeated three times. The concentration of bacteria in each sample was at the level of $10^{8} \mathrm{cfu} / \mathrm{mL}$, as the cell suspension was equivalent to the $0.5 \mathrm{McF}$ arland turbidity standard (McFarland densitometer DEN-1B, Biosan). ${ }^{45}$ After the final centrifugation step and supernatant removal, the pellets were suspended in $20 \mu \mathrm{L}$ of the sterile saline solution. About $5 \mu \mathrm{L}$ of each mixture was used for SERS measurements by placing it onto the SERS substrate $5 \mathrm{~min}$ before measurement (to let the sample dry). Each strain was cultured independently three times, both on solid (agar) and in liquid media. The scheme of the sample preparation for the SERS measurements is depicted in Figure 1a-c.

Instrumentation: SERS Spectroscopy, Scanning Electron Microscopy (SEM), and X-ray Diffraction (XRD). To perform SERS measurements, a Bruker's BRAVO spectrometer equipped with a Duo LASER (700-1100 nm) and a CCD camera was used. The spectrometer also has a function of fluorescence rejection, which was applied during all measurements. The laser power for both lasers was $<100 \mathrm{~mW}$, while the spectral resolution was $2-4 \mathrm{~cm}^{-1}$. The SERS spectra were recorded repeatedly for $30 \mathrm{~min}$. A single measurement, composed of three accumulations, each of $6 \mathrm{~s}$, was completed after approximately $45 \mathrm{~s}$ (because of data processing and transfer). The results were next processed via OPUS software, ver.2012 (Bruker Optic GmbH, Germany). All of the spectra presented in the article were averaged from at least 25 single measurements.

After SERS experiments, the SERS substrates with bacteria placed on them were subjected to SEM measurements, without prior treatment of the cells. The substrates were attached to aluminum SEM pin stubs with conductive liquid silver paint (Pelco, Ted Pella, Inc.). The SEM measurements, performed under high vacuum, were obtained using an FEI Nova NanoSEM 450 scanning electron microscope. The range of the accelerating voltage was $2-10 \mathrm{kV}$.
To assess the sizes of silver nanostructures building $\mathrm{Si} / \mathrm{Ag}$ substrates applied in the study, the X-ray diffraction (XRD) technique was used. The samples were analyzed using an Empyrean 2 (PANalytical) X-ray Diffraction System [radiation line $\mathrm{Cu} \mathrm{K} \alpha_{1}$ (KL3) was $1.540598 \AA$ and the analyzed reflex $\mathrm{Ag}(111)$ was at an angle of $2 \theta=38.116^{\circ}$.

Preparation of SERS Substrates. Silicon/Ag Platforms (Si/Ag Platforms). The preparation of the silicon-based SERS substrate consists of five main steps. First, the silicon wafer was cut into squares $\left(3.5 \times 3.5 \mathrm{~mm}^{2}\right)$ using a mechanical cutting saw (type: Disco DAD $2 \mathrm{H} / 6 \mathrm{TM})$ at the Institute of Electronic Materials Technology in Warsaw, Poland. Second, the silicon surfaces were washed with great care with deionized water. Next, all of the residues were removed and the cut wafers were dried in a stream of argon. Afterward, the silicon surface was modified with the use of a femtosecond laser (based on potassium yttrium tungstate, with $1030 \mathrm{~nm}$ wavelength, repetition rate $300 \mathrm{kHz}$, and a single pulse set to $300 \mathrm{fs}$ ). In the final step, the modified silicon surface was sputtered with $100 \mathrm{~nm}$ of silver (the target was purchased from Mennica Metale Szlachetne, Poland) via physical vapor deposition (PVD) (sputtering device: Quorum, Q150T ES, Laughton, U.K.). The vacuum during the process was at the level of $10^{-2} \mathrm{mbar}$, the sputtering current was $25 \mathrm{~mA}$, and the process took place in an argon plasma atmosphere. The final thickness of the silver layer was controlled with a quartz crystal monitor. The SEM and XRD analyses of the $\mathrm{Si} / \mathrm{Ag}$ substrates are presented in the Supporting Information (Figure $\mathrm{S} 2 \mathrm{a}, \mathrm{b}$ ).

Silver-Coated $\mathrm{Fe}_{2} \mathrm{O}_{3}\left(\mathrm{Fe}_{2} \mathrm{O}_{3} @ \mathrm{Ag}\right)$ Magnetic Nanoparticles. The synthesis procedure of $\mathrm{Fe}_{2} \mathrm{O}_{3} @ \mathrm{Ag}$ magnetic nanoparticles was inspired by a previously reported method ${ }^{46}$ and modified. The developed synthesis pathway is a one-step thermal decomposition of silver acetate salt in the presence of iron(III) oxide nanoparticles. $\mathrm{Fe}_{2} \mathrm{O}_{3}$ nanospheres having an average diameter of less than $50 \mathrm{~nm}$ (Merck KGaA, Darmstadt, Germany) were initially grated in an agate mortar with silver acetate (Merck KGaA, Darmstadt, Germany) in a mass ratio of 1:10. The mixture obtained in this way was transferred to plastic containers, and agate balls were added to it. Subsequently, the substrates were ground for $30 \mathrm{~min}$ in a Retsch MM400 mixer ball mill with a frequency of $20 \mathrm{~Hz}$. The obtained powder was transferred to a round-bottom boat ceramic crucible and placed in a Carbolite tube furnace (Keison Products, Chelmsford, Essex, U.K.). The mixture was heated up to $200{ }^{\circ} \mathrm{C}$ at a heating rate of $10{ }^{\circ} \mathrm{C} / \mathrm{min}$, and then, it was kept in a nitrogen atmosphere at $200{ }^{\circ} \mathrm{C}$ for $2 \mathrm{~h}$. The furnace was cooled to ambient temperature with the product kept in a protective nitrogen atmosphere. Next, the product was purified by suspending it in $500 \mathrm{~mL}$ of distilled water. Additionally, an ultrasonic bath was applied at this stage. Finally, the suspension was poured over the neodymium magnet till the supernatant became transparent. The final product was dried at ambient temperature because of which the nonmagnetic phase and all of the residuals from the synthesis were removed from the product in the supernatant phase. The SEM analysis and size distribution histogram of $\mathrm{Fe}_{2} \mathrm{O}_{3} @ \mathrm{AgNPs}$ are presented in the Supporting Information (Figure S2c,d).

Design and Implementation of the Microfluidic Chip. The layered diagram of the microfluidic system integrated with the magnetically controlled area containing the SERS-active platform is depicted in Figure S3a. The system included a quartz glass with dimensions of $20 \times 20 \mathrm{~mm}^{2}$, which allowed us to collect signals during the experiment. The microfluidic system was designed with the use of MasterCAM software and milled in a 5- and $2 \mathrm{~mm}$ polycarbonate (PC) slab (Bayer) with a computer numericalcontrolled (CNC) milling machine (ErgWind, type MFG4025P). To join two main milled elements, PC slabs were pressed together at a high temperature $\left(T=130{ }^{\circ} \mathrm{C}\right)$ for $30 \mathrm{~min}$. The top cover was connected to the rest of the chip with screws and sealed with an $\mathrm{O}$ ring. A technical drawing with dimensions is shown in Figure S3b.

An infusion pump system (Harvard Apparatus Pump Series, MA) was used for the automated control of the flow. For the injection of the analyte and the buffer into the microfluidic system and collection of the separated fractions, blunt-ended needles with an outer diameter of $0.8 \mathrm{~mm}$ were installed in the holes that were drilled in appropriate 


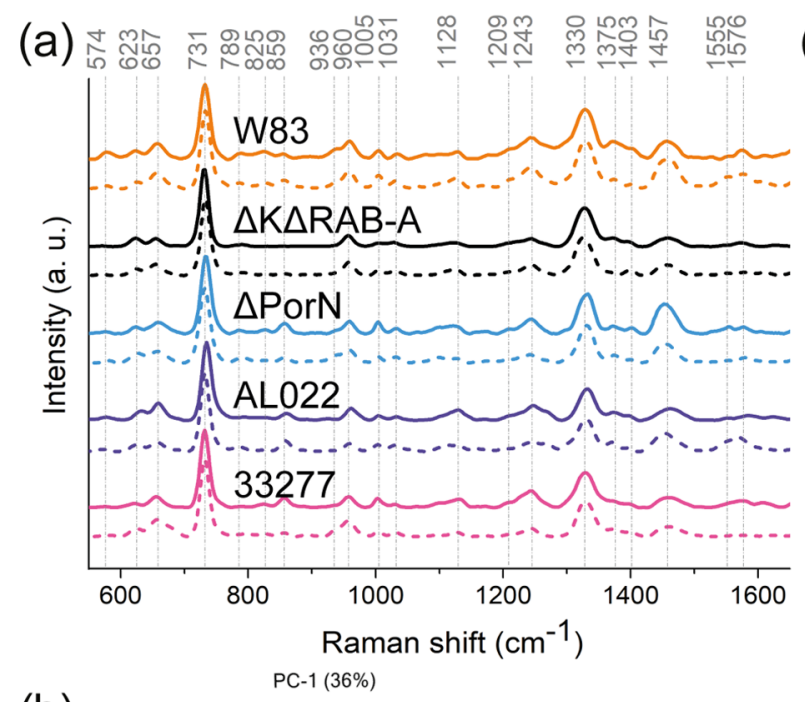

(b)

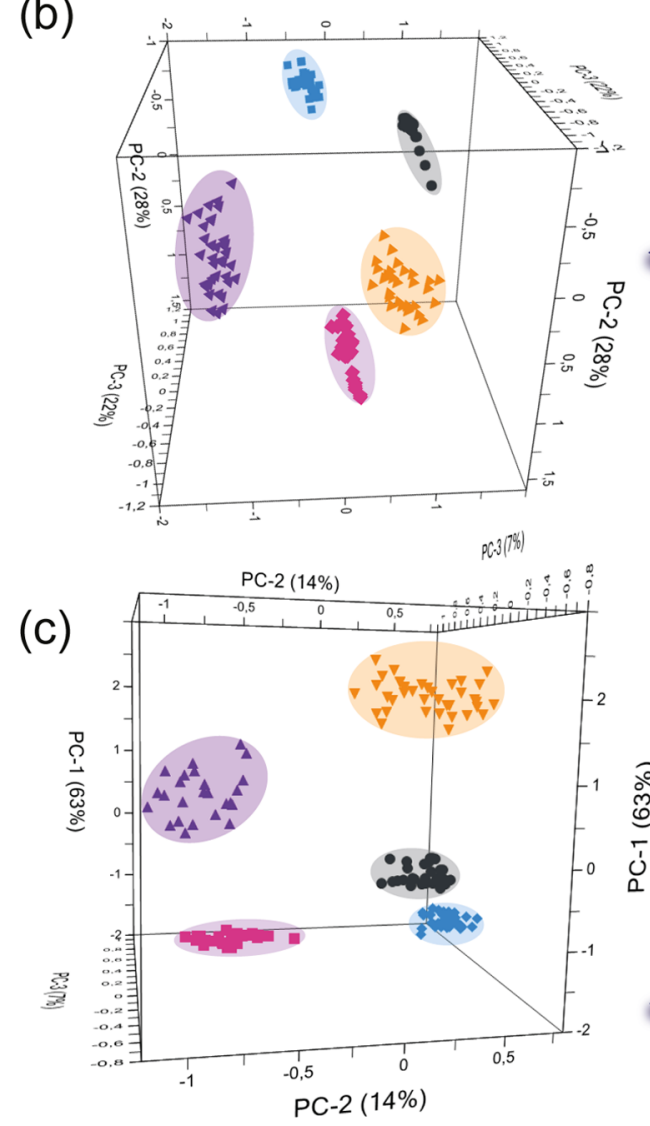

(d)
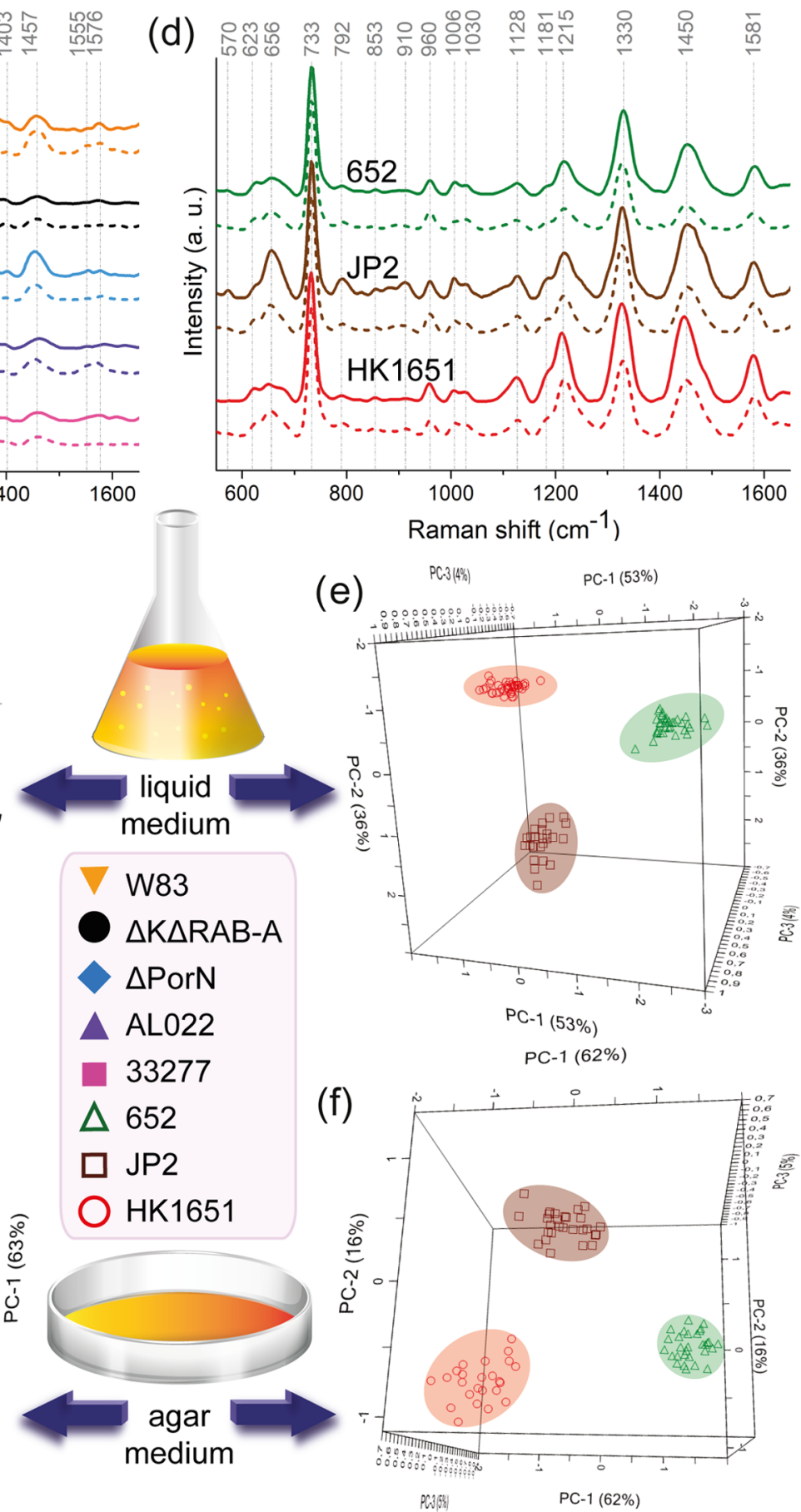

(e)
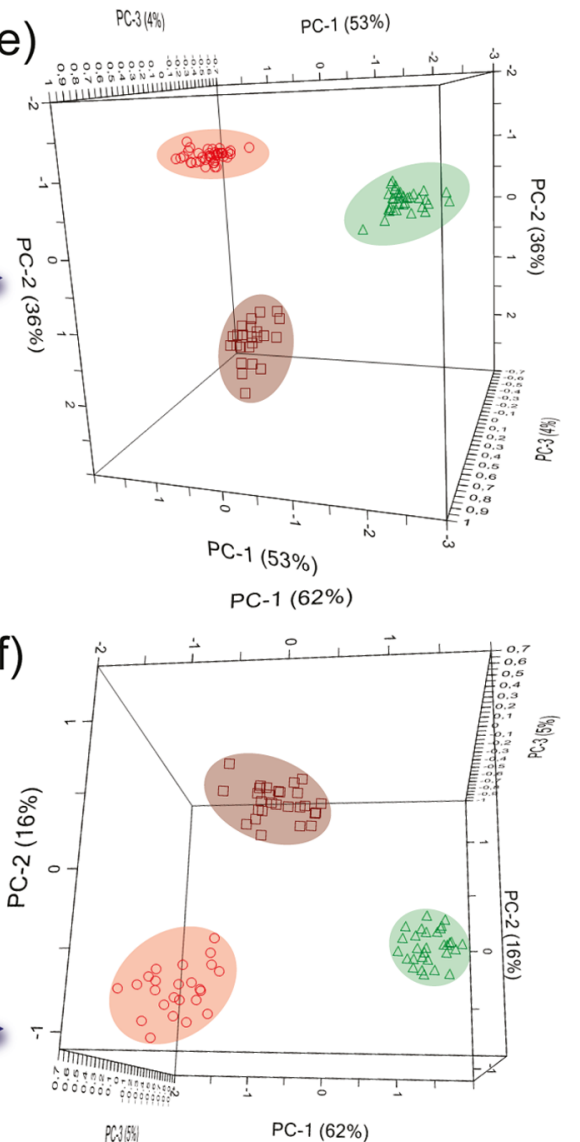

Figure 2. SERS spectra (a, d) and three-dimensional (3D) PCA plots (b, c, e, f) obtained for five investigated P. gingivalis strains (W83, $\Delta \mathrm{K}$ / $\triangle \mathrm{RAB}-\mathrm{A}, \triangle \mathrm{PorN}, \mathrm{AL} 022$, and 33277) and three A. actinomycetemcomitans strains (652, JP2, and HK1651). Spectra marked with solid lines in the images (a, d) and PCA results from the images (b, e) show results obtained for bacteria grown on agar media, while spectra marked with dashed lines in the images $(a, d)$ and PCA results from the images $(c, f)$ show results obtained for bacteria grown in liquid media.

places in the plates. Polyethylene (PE) tubings with an inner diameter of $0.8 \mathrm{~mm}$ were applied to connect the chip with an infusion syringe pump and a residue container.

\section{RESULTS AND DISCUSSION}

SEM Images and Reproducibility of SERS Measurements. In the present study, two pathogenic bacterial strains ( P. gingivalis and A. actinomycetemcomitans) were included to show the spectroscopic differences between them. Additionally, the differentiation between $P$. gingivalis and non- pathogenic streptococci (S. mitis, S. pseudopneumoniae) is presented. Such a distinction is of utmost importance, as all mentioned bacterial species can be found on the tooth surface and in the saliva; however, only $P$. gingivalis infection has been linked to i.a. rheumatoid arthritis and Alzheimer's disease.

The surface of the SERS substrate was visualized via SEM imaging, which allowed us to study the morphology of $\mathrm{Si} / \mathrm{Ag}$ platforms and demonstrate the adsorption of investigated bacterial cells to the surface of these platforms (see Figure 1df). The silicon plates covered with silver grains allowed for the 
(a)
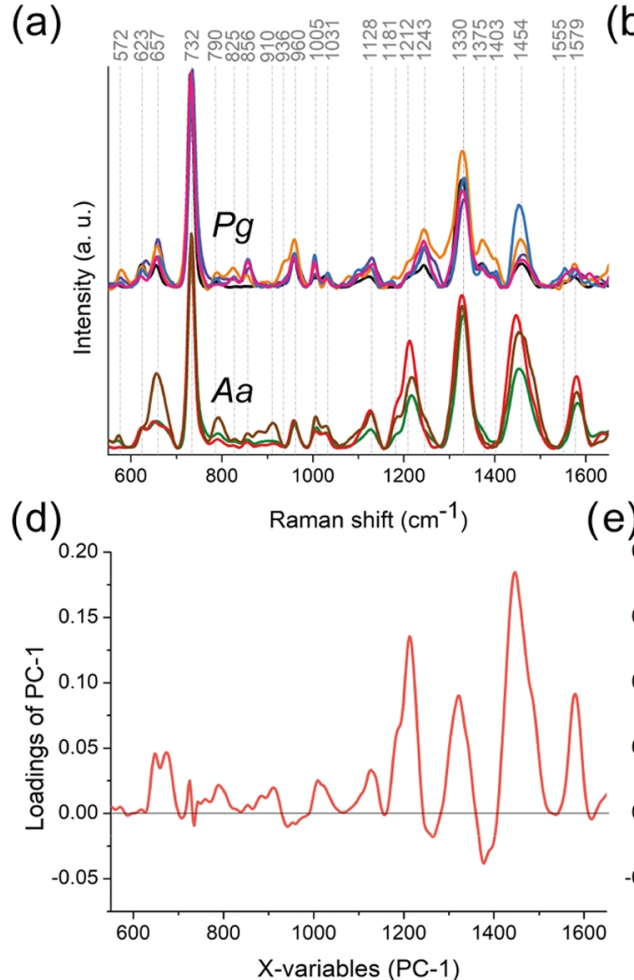

(g)

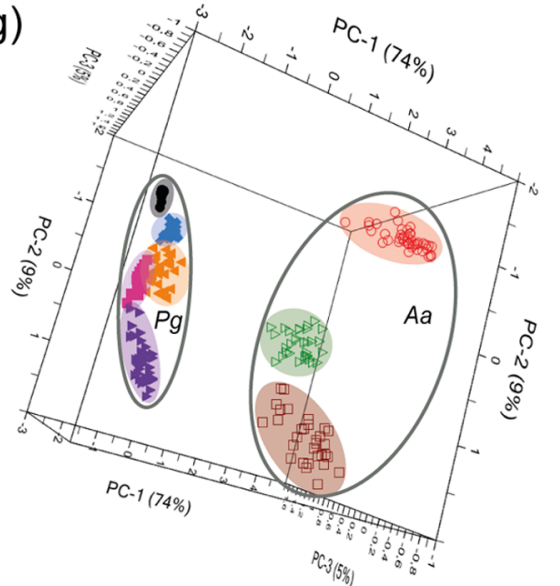

(h)
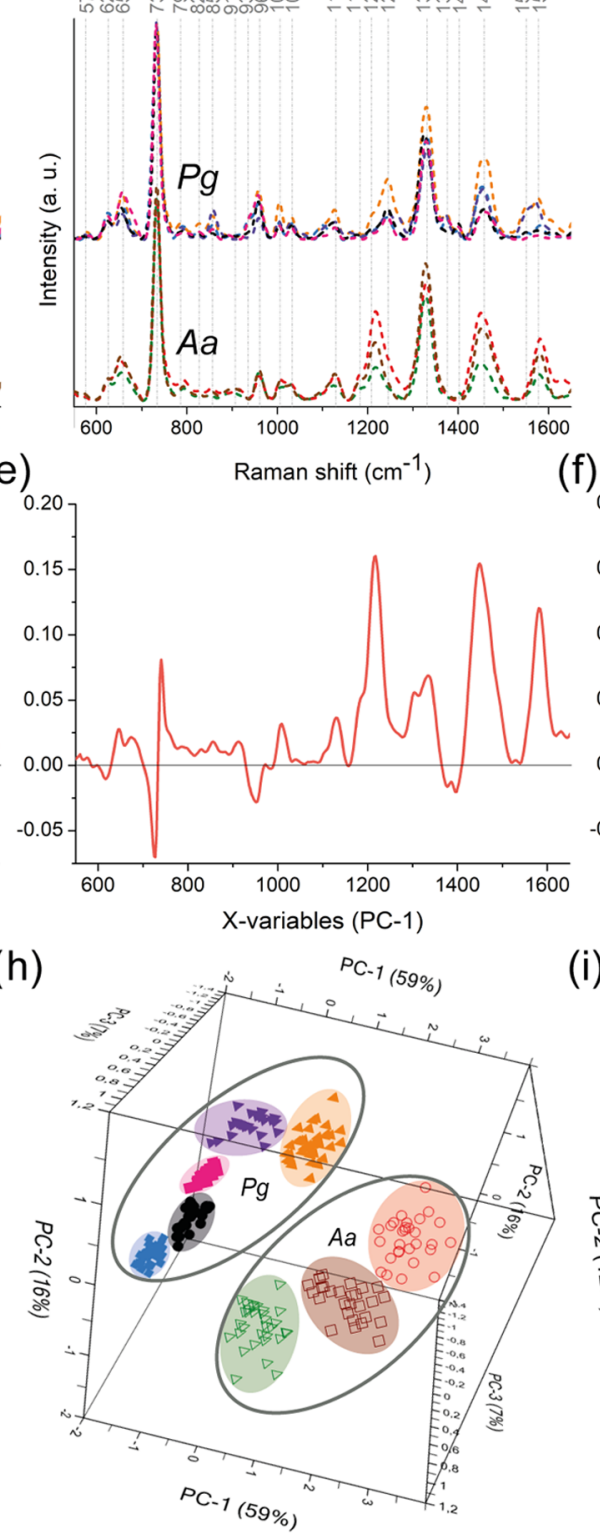

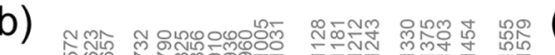

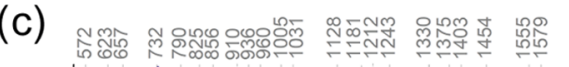
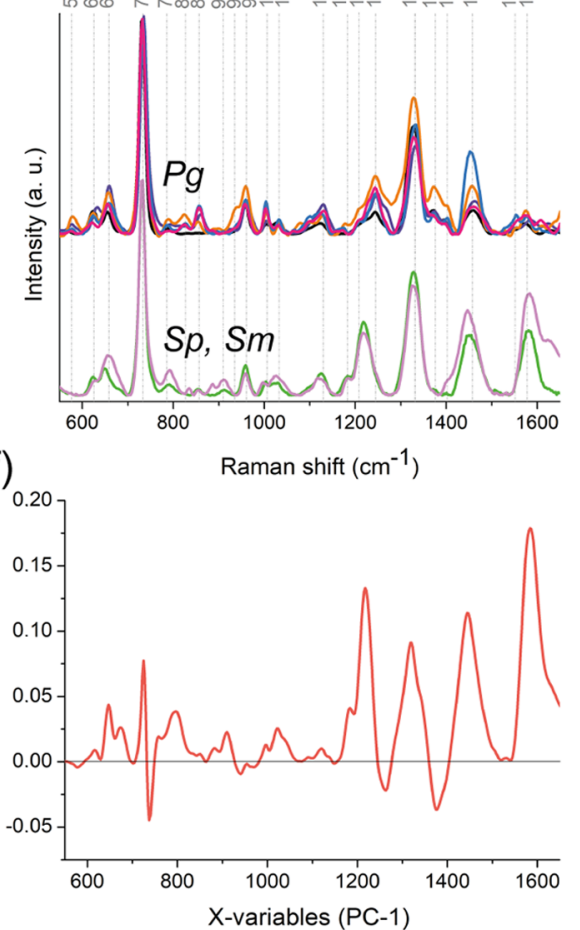

(i)
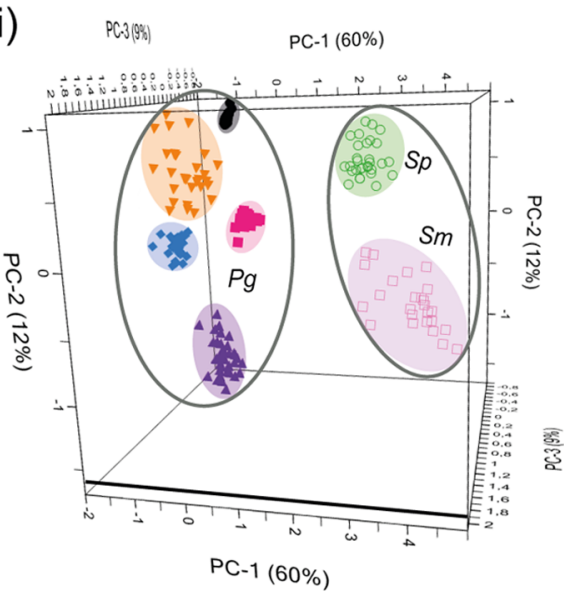
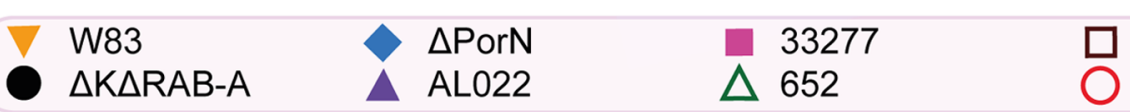

JP2

$3705 / 04$

HK1651

$6178 / 12$

Figure 3. Superimposed SERS spectra $(\mathrm{a}-\mathrm{c})$, loading plots $(\mathrm{d}-\mathrm{f})$, and PCA $(\mathrm{g}-\mathrm{i})$ of P. gingivalis (Pg), A. actinomycetemcomitans (Aa), and Streptococcus spp. (S. mitis, Sm, and S. pseudopneumoniae, Sp) strains. The loading plots allowed us to determine which bands are responsible for group separation in PCA while analyzing P. gingivalis together with A. actinomycetemcomitans or Streptococcus spp. The images (a, c, d, f, g, i) show results obtained for bacteria grown on agar media, while images $(b, e, h)$ show results obtained for bacteria grown on liquid media. The separation of all three bacterial genera $(\mathrm{Pg}, \mathrm{Aa}$, and $\mathrm{Sm} / \mathrm{Sp}$ ) is presented in the Supporting Information (Figure S5).

enhancement of the Raman signals of studied bacterial strains and to obtain reproducible SERS spectra (see Figure $1 \mathrm{~g}-\mathrm{i}$ ). As can be noticed, the individual SERS spectra of the same strain obtained by repeated scans are very similar to each other. On the other hand, when comparing the SERS spectra of different species, clear dissimilarities concerning band locations and intensities are observed. This proves that SERS substrates used in this study are appropriate to conduct SERS measurements of microbiological samples.

Investigation and Chemometric Analysis of Bacterial SERS Spectra Obtained on Si/Ag SERS Platforms. SERS Spectra of $P$. gingivalis. To check the ability of the SERS technique to differentiate strains of the same bacterial species, five strains of $P$. gingivalis were tested. The average results of the obtained SERS spectra, in the range from 550 to 1650 $\mathrm{cm}^{-1}$, are depicted in Figure $2 \mathrm{a}$ (the spectrum averaged over all P. gingivalis strains is depicted in Figure S4a,b). As one can notice, the spectra of all investigated strains show a high degree of similarity; each spectroscopic image is dominated by the bands at ca. 730 and $1330 \mathrm{~cm}^{-1}$, which can be assigned to the in-plane ring breathing mode of adenine and to $\mathrm{CH}_{3} / \mathrm{CH}_{2}$ wagging, respectively. ${ }^{47,48}$ The remaining observed bands can be attributed to metabolites of purine degradation other than adenine and AMP, e.g., guanine, xanthine, hypoxanthine, and 
uric acid, ${ }^{49}$ and to bacterial cell wall components, e.g., phospholipids $^{50}$ and proteins. ${ }^{51}$

The minute differences between spectra of studied strains may be attributed to the presence/absence of some antigens and/or secreted chemical substances, and to the metabolic profile of bacteria. ${ }^{49-51}$ This, in fact, applies when comparing any bacterial strains, irrespective of whether they are assigned to one or various species. The minor differences are also observed for the same bacterial strain, depending on whether it is cultured in the planktonic form (dashed lines in Figure 2a) or on agar plate (solid lines in Figure 2a). This may be associated with the culture conditions; as bacterial cells do not change locations on solid (agar) medium, they are constantly affected by metabolites secreted by them and other cells present in the same colony. This is not the case in liquid cultures incubated with shaking, as every bacterial cell constantly changes its location. As the SERS technique is known for its sensitivity at the level of a single molecule, the mentioned differences can be noticed in the SERS spectra of investigated bacteria. For this reason, it is very important to ensure identical measurement parameters and culture conditions for all compared bacterial strains. Nonetheless, despite the described dissimilarities, the main features characteristic for $P$. gingivalis species are still visible, especially the band at 1243 $\mathrm{cm}^{-1}$ assigned to amide III vibrations.

PCA Performed for SERS Spectra of P. gingivalis. The differences or similarities between the SERS spectra of $P$. gingivalis strains can be easily presented via principal component analysis (PCA). Figure 2b,c demonstrates 3DPCA separating five $P$. gingivalis strains cultured on solid (agar) and in liquid media, respectively. As can be noticed, the first three principal components (PC-1, PC-2, and PC-3) are responsible together for $86 \%$ of the variance in the data while comparing bacteria grown on agar media (Figure $2 \mathrm{~b}$ ) and for $84 \%$ of the variance in the data in the case of liquid cultures (Figure 2c). Such a result indicates that the SERS method is useful even when comparing strains similar from phenotypical, physiological, and biochemical points of view.

SERS Spectra of A. actinomycetemcomitans. Furthermore, to determine whether the SERS technique provides the possibility of distinguishing $P$. gingivalis from other bacterial strains associated with localized aggressive periodontitis, additional SERS measurements were performed, this time on three strains of $A$. actinomycetemcomitans. As previously performed, the measurements were conducted on bacteria grown on agar plates (solid lines in Figure 2d) and in the planktonic form (dashed lines in Figure 2d). The results averaged over all investigated $A$. actinomycetemcomitans strains are presented in Figure S4c,d. As can be observed, all of the spectra are very similar to each other, regardless of the strain and growth conditions. Similar to $P$. gingivalis, the spectra are dominated by the bands at around 733 and $1330 \mathrm{~cm}^{-1}$. Additionally, one can see strong bands at ca. 1215, 1450, and $1581 \mathrm{~cm}^{-1}$, which can be assigned to $\mathrm{C}-\mathrm{N}$ stretching/amide III/thymine, $\mathrm{CH}_{3} / \mathrm{CH}_{2}$ deformation, and the $\mathrm{C}=\mathrm{C}$ bending mode of phenylalanine, respectively. ${ }^{48}$ There are also numerous bands of lower intensities, e.g., at $623 \mathrm{~cm}^{-1}$ (C-C twisting in protein), ${ }^{51} 656 \mathrm{~cm}^{-1}(\mathrm{C}-\mathrm{S}$ stretching, hypoxanthine, xanthine, guanine), ${ }^{52,53} 960 \mathrm{~cm}^{-1}$ ( $\mathrm{C}=\mathrm{C}$ deformation, adenine, guanine, $\mathrm{NAD}^{+}$), ${ }^{54-56} 1006 \mathrm{~cm}^{-1}$ (phenylalanine, $\mathrm{C}-$ $\mathrm{C}$ aromatic ring stretching), ${ }^{54-56} 1128 \mathrm{~cm}^{-1}(=\mathrm{C}-\mathrm{O}-\mathrm{C}=$ in unsaturated fatty acids in lipids), ${ }^{56}$ and $1181 \mathrm{~cm}^{-1}$ (tyrosine). ${ }^{53}$ As these bands are reproducible in all individual
SERS measurements, they apparently represent an inherent feature of tested bacterial strains and also contribute to group separation in PCA. Such defined band locations and band intensities, which are characteristic for specific bacterial species, are very important for their taxonomic affiliation determined by the SERS technique.

PCA Performed for SERS Spectra of A. actinomycetemcomitans. The PCA results obtained for the three strains of $A$. actinomycetemcomitans are presented in Figure 2e,f. The PC-1, PC-2, and PC-3 values together yielded 93\% of the total variance in the case of strains cultured on agar plates and $83 \%$ when analyzing bacteria grown in the liquid medium. These results indicate that the SERS-PCA-based method enables distinction between closely related bacterial strains and thus their identification as different strains. Additionally, the accuracy of such an analysis is very high, making the proposed method consistent and reliable.

Comparison of SERS Spectra and PCA Results of $P$. gingivalis and $A$. actinomycetemcomitans. The proposed technique allows for differentiation between $P$. gingivalis and another common periodontal pathogen, A. actinomycetemcomitans, and for discrimination between strains belonging to the same species. This is best visualized by the direct comparison of the plotted-together SERS spectra obtained for the five strains of $P$. gingivalis and the three strains of $A$. actinomycetemcomitans (see Figure 3 ) both grown on agar plates (Figure $3 \mathrm{a}$ ) and in liquid cultures (Figure $3 \mathrm{~b}$ ). It can be easily noticed that these two pathogenic species differ in the region between 760 and $940 \mathrm{~cm}^{-1}$. While the SERS spectra of all $A$. actinomycetemcomitans strains exhibit weak band at ca. 910 $\mathrm{cm}^{-1}$, they are absent in the spectra of $P$. gingivalis. On the contrary, in the SERS spectra of $P$. gingivalis, the bands at ca. 860,1375 , and $1400 \mathrm{~cm}^{-1}$ are observed but are absent or very weak in the case of $A$. actinomycetemcomitans. The feature that is also worth noticing is located in the region between 1000 and $1050 \mathrm{~cm}^{-1}$. The bands at around 1005 and $1031 \mathrm{~cm}^{-1}$ in the spectra of $P$. gingivalis strains are well-separated, while in the spectra of $A$. actinomycetemcomitans they strongly overlap. The last but not least is a strong band located at $1243 \mathrm{~cm}^{-1}$, which, is absent in the spectra of the tested A. actinomycetemcomitans strains. This lack is compensated by the presence of the strong band at around $1215 \mathrm{~cm}^{-1}$ in the SERS spectra of $A$. actinomycetemcomitans, which in the case of $P$. gingivalis can be observed only as a weak shoulder at around $1209 \mathrm{~cm}^{-1}$.

All of the abovementioned differences are important for the recognition of well-separated groups in 3D-PCA. The most important SERS signatures responsible for cluster separation are located at around 1212,1330,1454, and $1579 \mathrm{~cm}^{-1}$, which can be observed in the loading plots (Figure 3d,e). These results apply both for bacteria cultured on agar medium (Figure 3d) and in broth (Figure 3e). The results obtained from 3D-PCA (see Figure $3 \mathrm{~g}, \mathrm{~h}$ ) indicate that the investigated bacterial strains can be easily divided into two clusters. The first one is grouping together the strains of $P$. gingivalis, while the second one is grouping together the strains of $A$. actinomycetemcomitans. The accuracy of this separation reached $88 \%$ in the case of bacteria grown on agar plates and $82 \%$ for bacteria from planktonic cultures. This clearly indicates that two tested periodontal pathogens can be easily distinguished in a fast and precise manner.

It is also important to note that all described differences are visible regardless of the type of the used medium, solid or 
Scheme 1. Magnetic-Based Separation of Bacteria from the Clinical Sample ${ }^{a}$

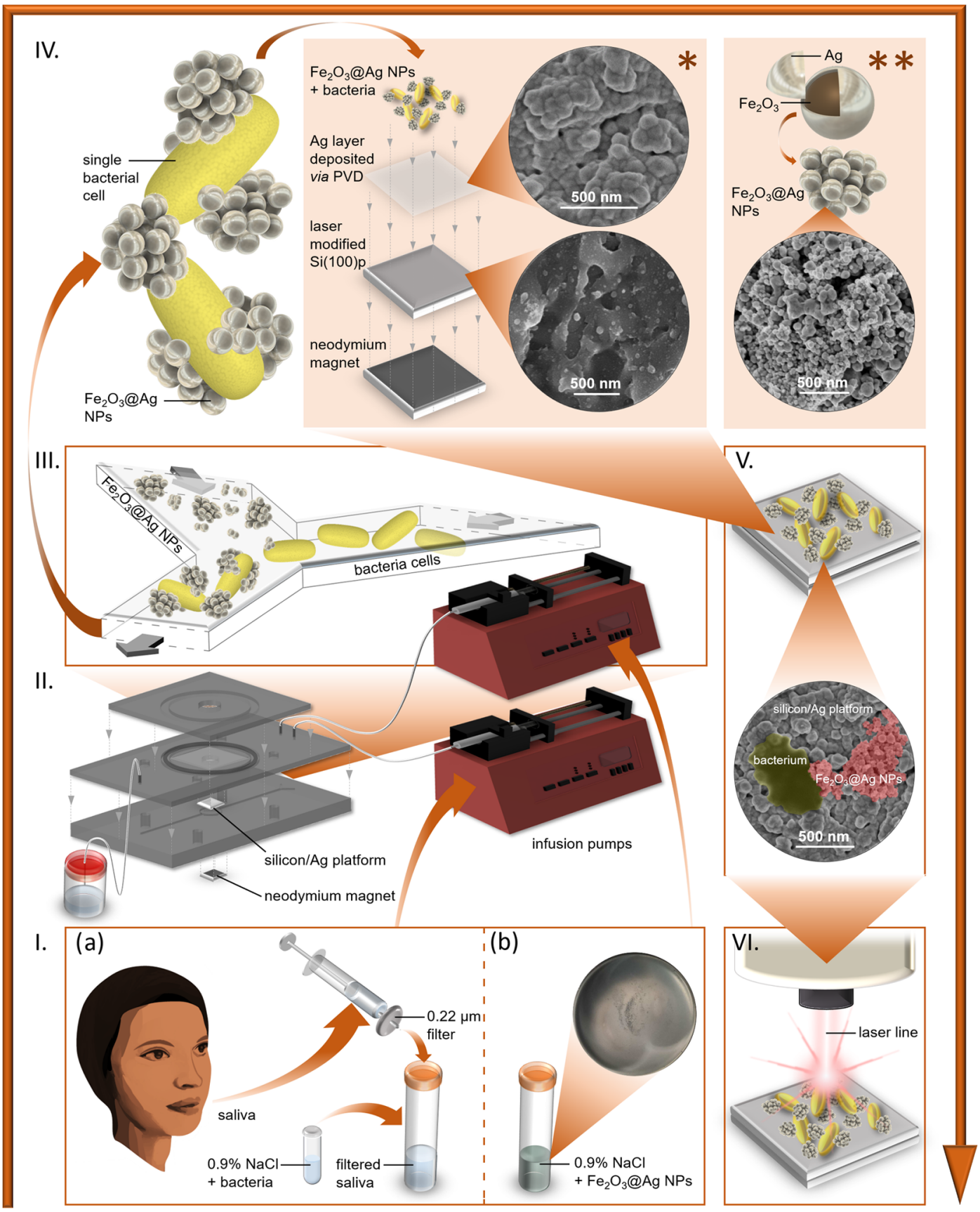

${ }^{a_{T}}$ The experiment comprised collection, filtration, and inoculation of human saliva (Ia); preparation of the solution of $\mathrm{Fe}_{2} \mathrm{O}_{3} @ \mathrm{AgNPs}$ (Ib); mixing both types of solutions in a microfluidic chip (II); adsorption of bacterial cells to $\mathrm{Fe}_{2} \mathrm{O}_{3} @ \mathrm{AgNPs}$ and formation of bacteria-NP aggregates (III); magnetic attraction of the aggregates to the $\mathrm{Si} / \mathrm{Ag}$ SERS platform placed over neodymium magnet (* and ** represent the arrangement and SEM images of the $\mathrm{Si} / \mathrm{Ag}$ substrate and of $\mathrm{Fe}_{2} \mathrm{O}_{3} @ \mathrm{Ag}$ magnetic NPs, respectively) (IV); adsorption of bacteria-NP aggregates to the Si/Ag SERS platform (V); and SERS measurements of the sample (VI).

liquid. This, in turn, demonstrates that the color of bacterial colonies formed on agar plates does not influence the obtained spectra. In the case of $A$. actinomycetemcomitans, the cells are pale white both in the liquid and solid media, while $P$. gingivalis wild-type strains exhibit black pigmentation when grown on blood agar and pale white when cultured in a broth. The appearance of the black pigment is due to accumulation of heme on the cell surface. ${ }^{37,57}$ This finding is crucial, as the presence of, e.g., artificial pigmentation of bacterial colonies due to the agar medium supplementation, usually affects the SERS spectra of bacteria. ${ }^{58}$

Comparison of SERS Spectra and PCA Results of $P$. gingivalis and Streptococcal Strains. Additionally, we compared the SERS spectra of strains belonging to $P$. gingivalis with those obtained for S. mitis 3705/04 and S. pseudopneumoniae 6178/12. The first streptococcal species is a common salivary microbiota, while the second one is an emerging respiratory tract pathogen, and thus it can also be detected in human saliva. As mentioned above, the SERS spectra obtained 

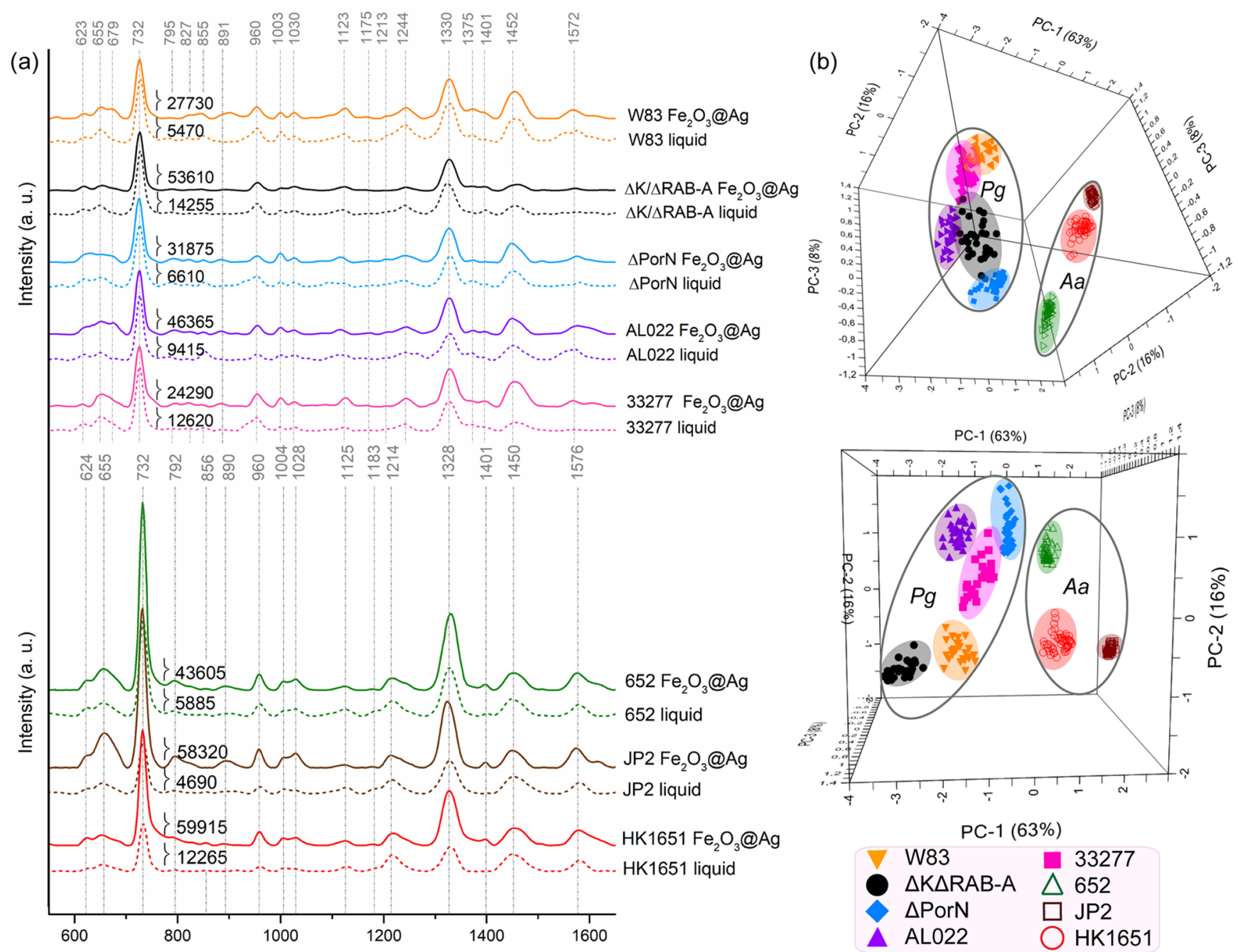

(c)

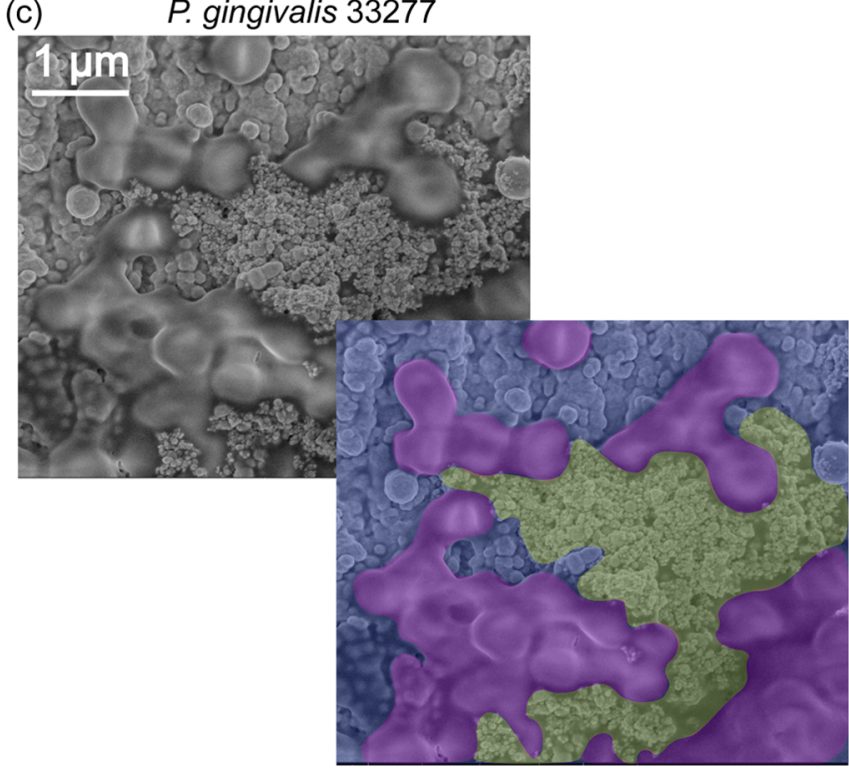

(d) A. actinomycetemcomitans 652

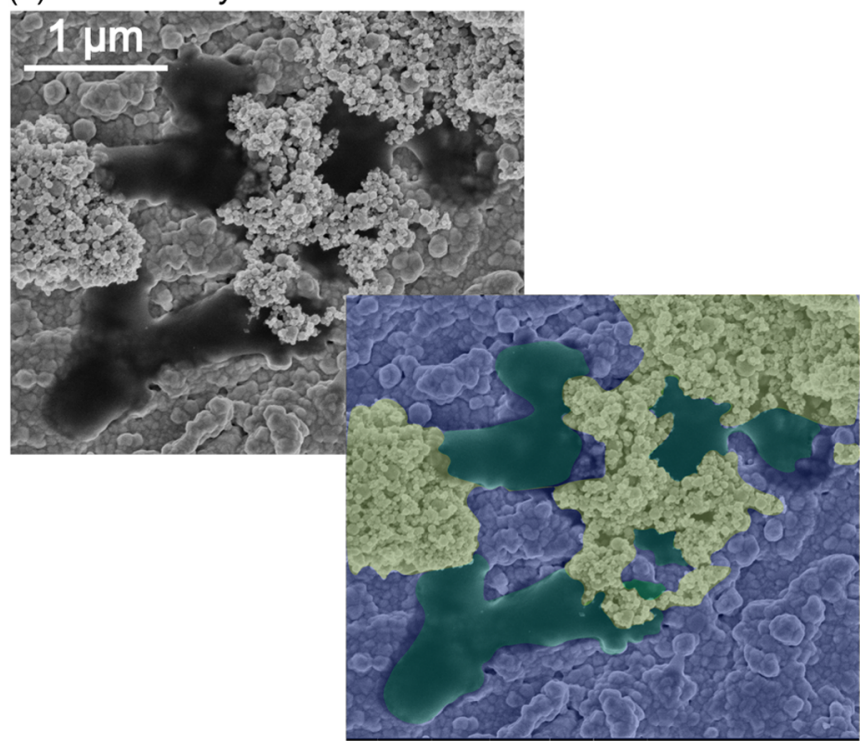

Figure 4. SERS spectra (a), PCA results (b), and SEM images (c, d) obtained for bacterial strains belonging to P. gingivalis or A. actinomycetemcomitans species. The spectra marked with solid lines show results obtained for bacteria grown in liquid media, which were next rinsed, and dispersed in the saline solution, mixed with $\mathrm{Fe}_{2} \mathrm{O}_{3} @ \mathrm{AgNPs}$, and magnetically attracted to the Si/Ag SERS substrate in the microfluidic chip. The spectra marked with dashed lines are given for comparison and show results obtained for bacteria grown in liquid media and placed over the $\mathrm{Si} / \mathrm{Ag}$ SERS substrate (also presented in Figure 2a,2d). The numbers given close to the band at around $730 \mathrm{~cm}^{-1}$ represent average counts for this particular band before normalization. 
for $P$. gingivalis strains differ from the spectra of streptococcal cells (Figure 3c). These dissimilarities refer especially to the bands at ca. 1185 and $1217 \mathrm{~cm}^{-1}$, which are present in the spectra of streptococci and absent in spectroscopic images of $P$. gingivalis. Attention should also be focused on the band at around $1580 \mathrm{~cm}^{-1}$, which is very weak for $P$. gingivalis strains and very strong in the case of streptococcal strains. For this reason, the band at $1580 \mathrm{~cm}^{-1}$ has the biggest contribution to group separation in PCA, which can be observed in the loading plot of PC-1 versus the Raman shift (see Figure 3f). The other important spectroscopic signatures that distinguish between these two groups of bacteria are located at 1217, 1328, and $1451 \mathrm{~cm}^{-1}$. A very similar observation was made when $A$. actinomycetemcomitans was compared to $P$. gingivalis (see Figure 3d,e). Despite this similarity, one should keep in mind that all, even weak, spectroscopic bands are involved in PCA. The results of PCA are shown in Figure 3i. PC-1 together with PC- 2 and PC-3 reached $81 \%$ of variability, proving once again that SERS coupled with PCA can serve as a fast and reliable differentiation method of bacterial cells.

The PCA and loading plot for all investigated strains belonging to $P$. gingivalis (33277, W83, $\Delta \mathrm{K} / \Delta \mathrm{RAB}-\mathrm{A}, \Delta \mathrm{PorN}$, AL022), A. actinomycetemcomitans (HK1651, 652, JP2), and Streptococcus spp. (S. mitis 3705/04, S. pseudopneumoniae $6178 / 12)$ are presented in Figure S5.

Investigation and Chemometric Analysis of Bacterial SERS Spectra Obtained by Applying $\mathrm{Fe}_{2} \mathrm{O}_{3} @ \mathrm{Ag}$ Magnetic NPs and Si/Ag Platforms. SERS Spectra and PCA of $P$. gingivalis and $A$. actinomycetemcomitans. In Scheme 1, we present the concept of the main experiment. The experiment was performed for two types of samples: bacterial cells mixed with $\mathrm{Fe}_{2} \mathrm{O}_{3} @ \mathrm{AgNPs}$ in (i) saline solution $(0.9 \%$ $\mathrm{NaCl}$ ) and (ii) filtered human saliva (for clarity, only the second variant is depicted in the scheme). The first variant was applied to check the functionality of the microfluidic system and whether the presence of an additional and differently prepared SERS substrate affects the spectroscopic image of bacteria. The results of SERS experiments, both for P. gingivalis and $A$. actinomycetemcomitans, are presented in Figure 4a. The second variant was performed to verify whether the system can be used to detect bacteria in clinical samples, such as human saliva (see the SERS-Based Bacteria Detection and Identification in Human Saliva section).

As can be noticed in Figure 4a, the similarities between SERS spectra of bacteria obtained by both types of SERS substrates and by applying only the $\mathrm{Si} / \mathrm{Ag}$ platform are visible with bare eyes (for band assignment, see SERS Spectra of P. gingivalis and SERS Spectra of A. actinomycetemcomitans sections). The biggest difference is the additional Raman signal enhancement, which is visualized by the number of counts for the band at around $730 \mathrm{~cm}^{-1}$ for each averaged spectrum (before normalization). This number is up to 1 order of magnitude higher in the case of spectra obtained by applying both $\mathrm{Si} / \mathrm{Ag}$ and $\mathrm{Fe}_{2} \mathrm{O}_{3} @ \mathrm{Ag}$ SERS substrates than on the bare $\mathrm{Si} / \mathrm{Ag}$ platform.

Such strong enhancement of the SERS signal is explainable. To elucidate this, one should realize the situation while placing bacterial cells on the SERS platform surface, which is well described in the article by Liu et al. ${ }^{59}$ The authors observed that during standard SERS measurements, cell structures, especially the cell wall and the membrane, do not penetrate the crevices of the SERS substrate, which results in relatively weak enhancement of Raman bands. When the authors used vancomycin, which inhibits peptidoglycan synthesis in the bacterial cell envelope, the cell structures started to penetrate the gaps of the SERS platform. As a consequence, the SERS signal of bacteria was amplified several times. A similar phenomenon, in the physical sense, probably occurs in the case of bacterial cells adsorbed to $\mathrm{Fe}_{2} \mathrm{O}_{3} @ \mathrm{AgNPs}$ and attracted magnetically to the $\mathrm{Si} / \mathrm{Ag}$ SERS substrate. In such a case, bacteria are affected by strong magnetic fields created by the neodymium magnet, and thus the cell structures easily penetrate into the crevices of the SERS platform.

The sizes of nanostructures building the applied SERS substrates offer another explanation for the observed SERS enhancement. The SEM analysis (Figure S2c,d) revealed that the median diameter of $\mathrm{Fe}_{2} \mathrm{O}_{3} @ A g N P s$ equals $41 \pm 2 \mathrm{~nm}$, while the XRD spectra (Figure S2a) demonstrated that $95.45 \%$ of the crystallites of silver present on the $\mathrm{Si} / \mathrm{Ag}$ platform have an average size of $33.8 \mathrm{~nm}$. Nonetheless, according to the SEM image of the $\mathrm{Si} / \mathrm{Ag}$ substrate (Figure S2a), these crystallites usually appear as agglomerates of $60-100 \mathrm{~nm}$ in diameter and create gaps of similar sizes. Thus, it is postulated that magnetic NPs occupy the free spaces between silver agglomerates on the silicon-based SERS substrate and create additional regions of intense local field enhancement caused by LSPR. Moreover, the described nanostructures are close to the optimal size of NPs for SERS. ${ }^{60}$

Finally, as it can be observed in Figure S6, the $\mathrm{Fe}_{2} \mathrm{O}_{3} @$ AgNPs densely surround the cell edges, creating a basket-like structure. This influences the formation of new spots being a source of additional amplification of analytical signals. Last but not least, bacteria, as objects characterized by a large surface area and volume in relation to mentioned spots, show a large cross section for interaction with the recorded backscattered radiation. Therefore, a significant part of the scattered radiation may not reach the detector at all. As NPs locate at the cell edges, the backscattered Raman radiation almost does not interact with the cell structures, in contrast to silver nanostructures of the $\mathrm{Si} / \mathrm{Ag}$ platform that are situated under the cell.

Due to the strong enhancement of the Raman signal, it is possible to detect relatively low concentrations of bacterial cells in the investigated sample. The obtained limit of detection (LOD) was at the level of $10^{3} \mathrm{cfu} / \mathrm{mL}$ (see Figure S7). Such a LOD value is sufficient to detect bacteria in human saliva, where the expected concentration is usually in the range between $10^{4}$ and $10^{8} \mathrm{cfu} / \mathrm{mL} .^{61,62}$

3D-PCA (see Figure 4b) demonstrated the possibility of separating five strains belonging to $P$. gingivalis and three strains of $A$. actinomycetemcomitans (similar to 3D-PCA presented in Figure 3g,h). As can be noticed, PC-1 together with PC-2 and PC-3 is responsible for $87 \%$ of the variance in the data when compared with these two species.

SEM Images of $P$. gingivalis and A. actinomycetemcomitans. The SEM images of $P$. gingivalis 33277 (Figure 4c) and $A$. actinomycetemcomitans 652 (Figure $4 \mathrm{~d}$ ) are presented in duplicates. The top row demonstrates unmodified SEM photographs, while the bottom row shows the same but postproduction colored photographs to highlight individual elements or structures: bacterial cells (marked with pink or green color), $\mathrm{Si} / \mathrm{Ag}$ platform (marked with blue), and $\mathrm{Fe}_{2} \mathrm{O}_{3} @$ AgNPs (marked with yellow). Signal enhancement obtained after simultaneous application of two different SERS substrates indicates that $\mathrm{Fe}_{2} \mathrm{O}_{3} @ \mathrm{AgNPs}$ have a significant contribution to the overall SERS effect. 


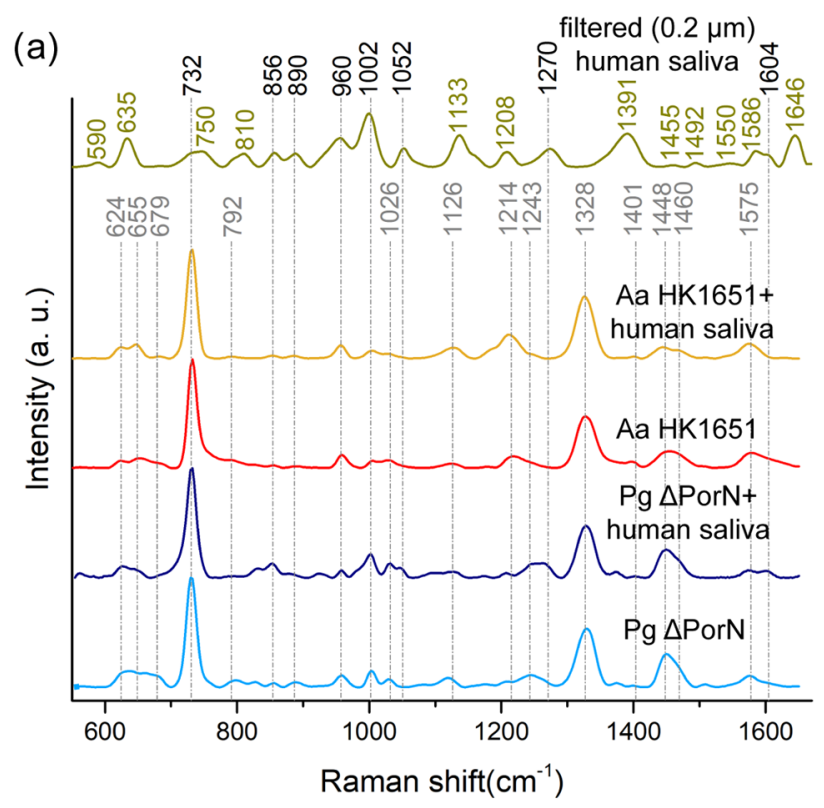

(b) $\quad \mathrm{PC}-1(78 \%)$

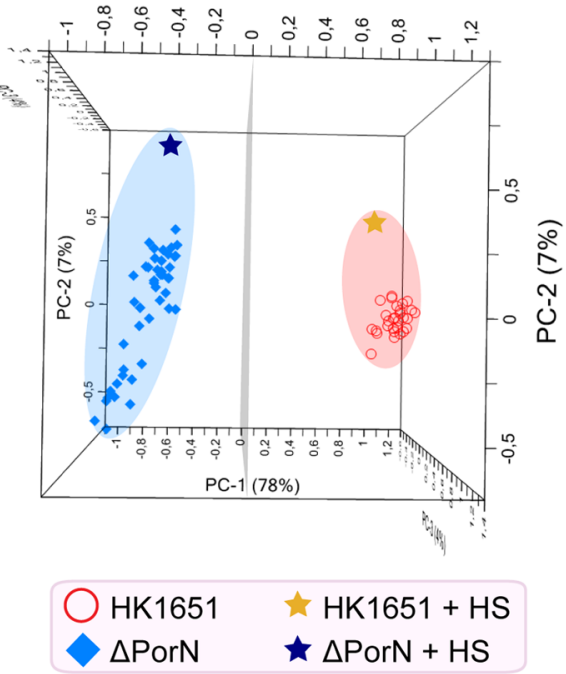

(c) P. gingivalis $\triangle$ PorN

(d) A. actinomycetemcomitans HK1651
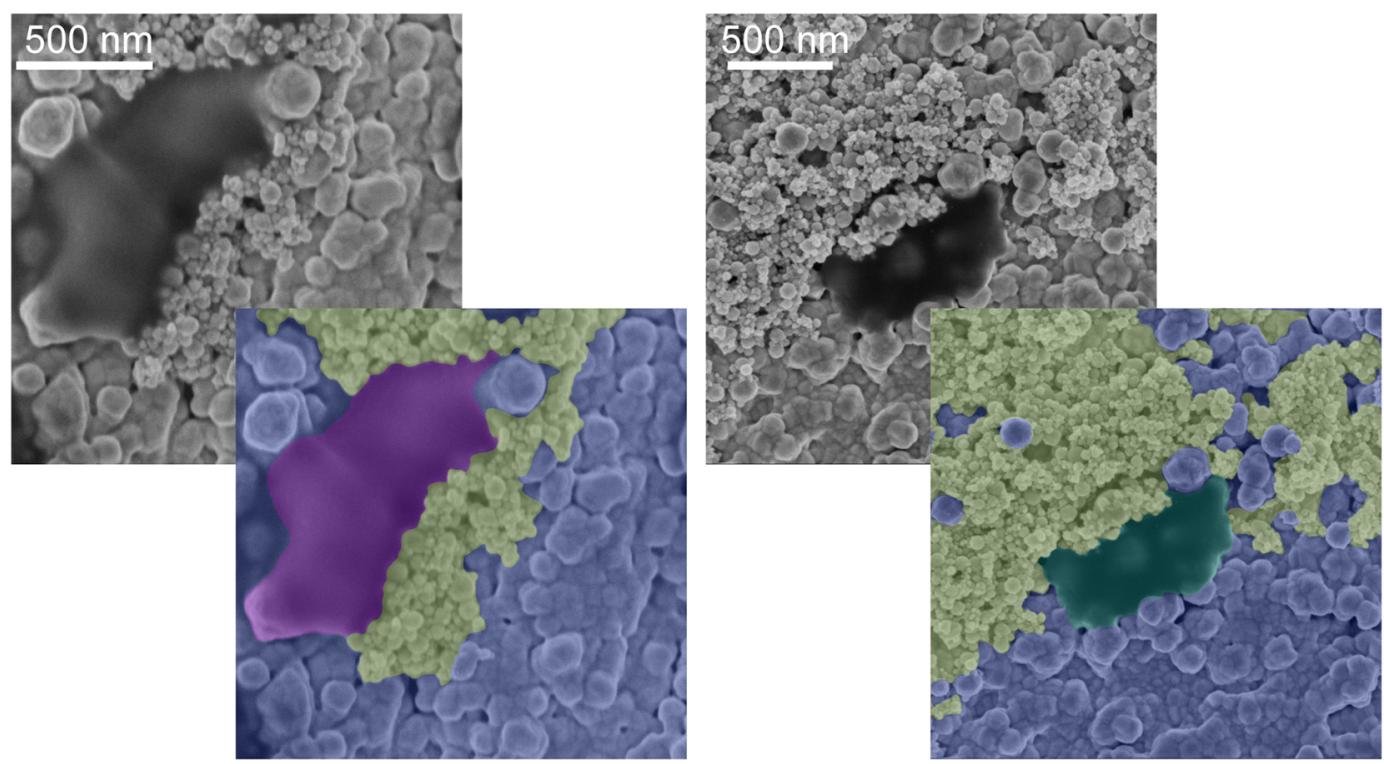

Figure 5. SERS spectra (a), PCA (b), and SEM images (c, d) obtained for two selected bacterial strains belonging to P. gingivalis $\triangle$ PorN or A. actinomycetemcomitans $\mathrm{HK} 165$, both mixed with human saliva (HS) and $\mathrm{Fe}_{2} \mathrm{O}_{3} @ A g N P s$, and magnetically attracted to the Si/Ag SERS substrate in microfluidic chip. All of the spectra represent bacteria previously grown in liquid media. The spectra of filtered human saliva, $P$. gingivalis $\Delta$ PorN, and A. actinomycetemcomitans HK1651 in (a) were given for comparison.

The SEM images demonstrating bacteria and $\mathrm{Fe}_{2} \mathrm{O}_{3} @$ AgNPs on the $\mathrm{Si} / \mathrm{Ag}$ platform corroborate with our observation presented earlier. As can be noticed, each bacterium is adsorbed to magnetic NPs or connected to other cell(s) (see Figures 4c,d and S6). This is associated with the action of the silver shell of NPs against Gram-negative bacteria, or, more precisely, with the interaction of nano-Ag with sulfur- or phosphorus-containing proteins building the bacterial cell wall. ${ }^{63}$ Moreover, as the core of $\mathrm{Fe}_{2} \mathrm{O}_{3} @$ AgNPs exhibits strong magnetic properties, it is possible to attract (via the neodymium magnet) NPs adsorbed to bacterial cells directly from liquid samples to the surface of the Si/Ag SERS substrate.

SERS-Based Bacterial Detection and Identification in Human Saliva. The microfluidic system served also to detect single bacterial cells in human saliva. For this purpose, the sample of filtered saliva collected from a healthy volunteer was investigated via the SERS method. Subsequently, two different bacterial strains ( $P$. gingivalis $\Delta$ PorN and $A$. actinomycetemcomitans HK1651) were separately mixed with $1 \mathrm{~mL}$ of filtered human saliva and then with $1 \mathrm{~mL}$ of the $0.9 \% \mathrm{NaCl}$ aqueous solution of magnetic NPs (with a concentration of $1 \mathrm{mg} / \mathrm{mL}$ ) in a microfluidic chip. The flow in both inlet channels was set at $100 \mu \mathrm{L} / \mathrm{min}$. The results of this experiment are presented in Figure 5a.

The averaged SERS spectrum of filtered human saliva mixed with $\mathrm{Fe}_{2} \mathrm{O}_{3} @ \mathrm{Ag}$ and placed over the $\mathrm{Si} / \mathrm{Ag}$ substrate shows various characteristic bands at around $635(\mathrm{C}-\mathrm{C}$ twisting of tyrosine), 750 (ring breathing mode of tryptophan), 810 (uric acid), 856 (ring breathing mode of tyrosine), 890 (structural 
protein modes, uric acid), 960 (hydroxyapatite, xanthine), 1002 (phenylalanine's C-C twisting), 1052 and 1133 (C-O stretching in carbohydrates and $\mathrm{C}-\mathrm{N}$ stretching in proteins), 1208 (tryptophan, tyrosine, phenylalanine-protein assignment), 1270 (amide III band in proteins), 1391 ( $\mathrm{CH}$ rocking), 1586 (phenylalanine, hydroxyproline, hypoxanthine), 1604 ( $\mathrm{C}=\mathrm{C}$ in-plane bending mode of phenylalanine and tyrosine), and $1646 \mathrm{~cm}^{-1}$ (amide I). ${ }^{48,64,65}$ These results highly correspond with the results presented in the literature ${ }^{65}$ (slight differences may be attributed to the filtration process, which was applied in the present study).

Despite the fact that the spectrum of human saliva has many bands, their contribution in the spectra of bacteria mixed with saliva is almost unnoticeable or minute, which can be observed in Figure 5a. The differences are limited to a slight increase in the intensity of the bands at around 1126 and $1214 \mathrm{~cm}^{-1}$ for $A$. actinomycetemcomitans HK1651 mixed with saliva compared to A. actinomycetemcomitans HK1651 suspended in the saline solution, which is probably because of the fact that the spectrum of filtered human saliva exhibits bands almost in the same regions (1133 and $1208 \mathrm{~cm}^{-1}$ ). In the case of $P$. gingivalis $\Delta$ PorN mixed with saliva, one can notice the increase in the intensity of the bands at around 856 and $1002 \mathrm{~cm}^{-1}$ in comparison with $P$. gingivalis $\Delta$ PorN suspended in saline. Moreover, additional weak bands at ca. 1052, 1270, and 1604 $\mathrm{cm}^{-1}$ appeared. All mentioned bands can be assigned to compounds present in human saliva.

To demonstrate that the SERS-based technique can serve as a method for bacterial identification in clinical samples, the spectra of human saliva samples containing $P$. gingivalis $\Delta$ PorN $(\Delta$ PorN $+\mathrm{HS})$ or A. actinomycetemcomitans HK1651 $($ HK1651 + HS) were averaged and analyzed via 3D-PCA together with measurements performed for $P$. gingivalis $\triangle$ PorN and $A$. actinomycetemcomitans HK1651 in saline. The results shown in Figure $5 \mathrm{~b}$ demonstrate that yellow $(\Delta$ PorN $+\mathrm{HS})$ and navy blue (HK1651 + HS) stars, representing the mentioned averaged spectra, are located in close proximity to the groups representing the SERS measurement of $P$. gingivalis $\Delta$ PorN and $A$. actinomycetemcomitans HK1651 in saline solution, respectively. The $\mathrm{PC}-1$ reached $78 \%$ of total variance and together with PC-2 and PC-3 the value of $89 \%$ was obtained. This clearly proves that different bacterial species can be easily detected in clinical samples such as saliva, distinguished from each other, and taxonomically identified by the SERS-PCA-based technique.

The SEM images of $P$. gingivalis $\triangle$ PorN (Figure 5c) and $A$. actinomycetemcomitans HK1651 (Figure 5d) reveal singular bacterial cells adsorbed to magnetic NPs and the $\mathrm{Si} / \mathrm{Ag}$ platform. The cells were previously suspended in human saliva, mixed with $\mathrm{Fe}_{2} \mathrm{O}_{3} @ \mathrm{AgNPs}$ in the microfluidic chip, and then attracted to the $\mathrm{Si} / \mathrm{Ag}$ SERS substrate via the neodymium magnet.

\section{CONCLUSIONS}

Here, we described the development of an easy, fast, and sensitive method for identification of pathogens causing periodontal disease. We presented that it is possible to obtain the intense and unique SERS spectra of bacterial cells in ca. 45 s, using only $\mathrm{Si} / \mathrm{Ag}$ substrates and a portable Raman spectrometer. Moreover, PCA allowed us to separate the SERS spectra of bacteria belonging to different species $(82,88$, and $91 \%$ of accuracy, depending on the analyzed sample). Such good separation coupled with very fast identification is an undisputed advantage of the SERS technique. The similar effect was also obtained for bacterial strains belonging to the same species.

Additionally, we proved that it is possible to detect and identify $P$. gingivalis and $A$. actinomycetemcomitans strains in clinical samples such as human saliva. For this purpose, the $\mathrm{Si}$ / $\mathrm{Ag}$ platform, $\mathrm{Fe}_{2} \mathrm{O}_{3} @ \mathrm{Ag}$ magnetic NPs, and the microfluidic chip were applied. As a result, the formation of bacteria-NP aggregates, magnetic separation, and Raman signal enhancement of bacteria were achieved. The obtained SERS signal was relatively strong, which is very beneficial, especially when detecting low concentrations of bacteria in clinical samples. Additionally, the PCA performed for bacteria suspended in human saliva allowed us to separate $P$. gingivalis from $A$. actinomycetemcomitans strains with $89 \%$ accuracy. Furthermore, the sample can be prepared in a rapid and label-free manner. There is also no need for expensive reagents. This, in turn, may lead to lowering the costs for the healthcare industry by early detection of ongoing infection and stopping illness development. The identification of different strains is additionally beneficial as strains of the same species often have different virulence potentials (described as pathotypes or serotypes) and therefore may pose various threats to human health.

Rapid detection and identification of $P$. gingivalis offered by the SERS-PCA technique are potentially of great importance for human health, as they provide unmatched diagnostic power essential for prevention of the development of chronic infection of periodontal tissues, which could lead to tooth loss, and comorbidities such as cardiovascular diseases, rheumatoid arthritis, and some cancer pathologies. Recent reports suggest that $P$. gingivalis may also be involved in Alzheimer's disease. Thus, in the near future, we plan to apply the SERS-PCA-based technique for $P$. gingivalis detection in the blood and the cerebrospinal fluid. This enables early and appropriate patient treatment to reduce the incidence of diseases associated with $P$. gingivalis proliferation in the periodontal pockets and thus its systemic dissemination.

\section{ASSOCIATED CONTENT}

\section{Supporting Information}

The Supporting Information is available free of charge at https://pubs.acs.org/doi/10.1021/acssensors.1c00166.

Generation of $P$. gingivalis AL022 ( $\triangle \mathrm{PGN}$ 1642) mutant strain and its genetic analysis; analysis of the diameter of SERS-active nanostructures based on SEM images or XRD spectra; detailed scheme of the microfluidic chip used for magnetic separation of bacterial cells from liquid samples; superimposed SERS spectra of all investigated $P$. gingivalis and $A$. actinomycetemcomitans strains cultured both on agar and in liquid media; the PCA and loading plots of P. gingivalis together with A. actinomycetemcomitans and Streptococcus spp.; additional SEM images presenting $P$. gingivalis and A. actinomycetemcomitans adsorbed to $\mathrm{Fe}_{2} \mathrm{O}_{3} @$ AgNPs and attracted to the $\mathrm{Si} / \mathrm{Ag}$ platform via the neodymium magnet; and limit of detection (LOD) measured for bacterial samples after applying the SERS-microfluidicbased method (PDF) 


\section{AUTHOR INFORMATION}

\section{Corresponding Authors}

Evelin Witkowska - Institute of Physical Chemistry, Polish Academy of Sciences, 01-224 Warsaw, Poland; $\odot$ orcid.org/ 0000-0003-2540-8822; Email: ewitkowska@ichf.edu.pl

Agnieszka Kamińska - Institute of Physical Chemistry, Polish Academy of Sciences, 01-224 Warsaw, Poland;

Email: akamin@ichf.edu.pl

\section{Authors}

Anna M. Łasica - Department of Bacterial Genetics, Institute of Microbiology, Faculty of Biology, University of Warsaw, 02-096 Warsaw, Poland

Krzysztof Niciński - Institute of Physical Chemistry, Polish Academy of Sciences, 01-224 Warsaw, Poland

Jan Potempa - Department of Microbiology, Faculty of Biochemistry, Biophysics, and Biotechnology, Jagiellonian University, 30-387 Krakow, Poland; Oral Immunology and Infectious Diseases, University of Louisville School of Dentistry, Louisville, Kentucky 40202, United States

Complete contact information is available at:

https://pubs.acs.org/10.1021/acssensors.1c00166

\section{Author Contributions}

${ }^{\perp}$ A.M.E. and K.N. contributed equally to this work.

\section{Funding}

E.W., K.N., and A.K. are grateful for the financial support from Foundation for Polish Science under Grant Team-Tech/20174/23 (POIR.04.04.00-00-4210/17-00). A.M.Ł. was supported by the National Science Centre Grant MINIATURA 1 no. 2017/01/X/NZ1/01378. J.P. is grateful for the financial support from NIH: NIH/NIDCR (DE 022597).

\section{Notes}

The authors declare no competing financial interest.

\section{ACKNOWLEDGMENTS}

The authors thank Prof. Anna Skoczyńska and Prof. Donald R. Demuth for providing the bacterial strains used in the present study and Dr. Arkadiusz Gajek for XRD analysis.

\section{REFERENCES}

(1) Haynes, C. L.; McFarland, A. D.; Van Duyne, R. P. SurfaceEnhanced Raman Spectroscopy. Anal. Chem. 2005, 77, 338A-346A.

(2) Jaworska, A.; Fornasaro, S.; Sergo, V.; Bonifacio, A. Potential of Surface Enhanced Raman Spectroscopy (SERS) in Therapeutic Drug Monitoring (TDM). A Critical Review. Biosensors 2016, 6, No. 47.

(3) Mosier-Boss, P. A. Review of SERS Substrates for Chemical Sensing. Nanomaterials 2017, 7, No. 142.

(4) Smith, E.; Dent, G. Surface-Enhanced Raman Scattering and Surface-Enhanced Resonance Raman Scattering. In Modern Raman Spectroscopy-A Practical Approach; John Wiley \& Sons, Ltd., 2005.

(5) Ding, S.-Y.; You, E.-M.; Tian, Z.-Q.; Moskovits, M. Electromagnetic theories of surface-enhanced Raman spectroscopy. Chem. Soc. Rev. 2017, 46, 4042-4076.

(6) Kneipp, K. Surface-enhanced Raman scattering. Phys. Today 2007, 60, 40-46.

(7) Park, W.-H.; Kim, Z. H. Charge Transfer Enhancement in the SERS of a Single Molecule. Nano Lett. 2010, 10, 4040-4048.

(8) Lombardi, J. R.; Birke, R. L.; Sanchez, L. A.; Bernard, I.; Sun, S. C. The effect of molecular structure on voltage induced shifts of charge transfer excitation in surface enhanced Raman scattering. Chem. Phys. Lett. 1984, 104, 240-247.
(9) Le Ru, E. C.; Blackie, E.; Meyer, M.; Etchegoin, P. G. Surface Enhanced Raman Scattering Enhancement Factors: A Comprehensive Study. J. Phys. Chem. C 2007, 111, 13794-13803.

(10) Le Ru, E. C.; Etchegoin, P. G. Single-Molecule SurfaceEnhanced Raman Spectroscopy. Annu. Rev. Phys. Chem. 2012, 63, 65-87.

(11) Jamieson, L. E.; Asiala, S. M.; Gracie, K.; Faulds, K.; Graham, D. Bioanalytical Measurements Enabled by Surface-Enhanced Raman Scattering (SERS) Probes. Annu. Rev. Anal. Chem. 2017, 10, 415437.

(12) Zhang, C.; Li, C.; Yu, J.; Jiang, S.; Xu, S.; Yang, C.; Liu, Y. J.; Gao, X.; Liu, A.; Man, B. SERS activated platform with threedimensional hot spots and tunable nanometer gap. Sens. Actuators, $B$ 2018, 258, 163-171.

(13) Zhao, X.; Liu, C.; Yu, J.; Li, Z.; Liu, L.; Li, C.; Xu, S.; Li, W.; Man, B.; Zhang, C. Hydrophobic multiscale cavities for highperformance and self-cleaning surface-enhanced Raman spectroscopy (SERS) sensing. Nanophotonics 2020, 9, 4761-4773.

(14) Witkowska, E.; Jagielski, T.; Kaminska, A.; Kowalska, A.; Hryncewicz-Gwozdz, A.; Waluk, J. Detection and identification of human fungal pathogens using surface-enhanced Raman spectroscopy and principal component analysis. Anal. Methods 2016, 8, 8427-8434.

(15) Guerrini, L.; Pazos-Perez, N.; Garcia-Rico, E.; Alvarez-Puebla, R. Cancer characterization and diagnosis with SERS-encoded particles. Cancer Nanotechnol. 2017, 8, No. 5.

(16) Lee, S.; Chon, H.; Lee, J.; Ko, J.; Chung, B. H.; Lim, D. W.; Choo, J. Rapid and sensitive phenotypic marker detection on breast cancer cells using surface-enhanced Raman scattering (SERS) imaging. Biosens. Bioelectron. 2014, 51, 238-243.

(17) Driskell, J. D.; Zhu, Y.; Kirkwood, C. D.; Zhao, Y.; Dluhy, R. A.; Tripp, R. A. Rapid and Sensitive Detection of Rotavirus Molecular Signatures Using Surface Enhanced Raman Spectroscopy. PLoS One 2010, 5, No. e10222.

(18) Feliu, N.; Hassan, M.; Garcia Rico, E.; Cui, D.; Parak, W.; Alvarez-Puebla, R. SERS Quantification and Characterization of Proteins and Other Biomolecules. Langmuir 2017, 33, 9711-9730.

(19) Durmanov, N. N.; Guliev, R. R.; Eremenko, A. V.; Boginskaya, I. A.; Ryzhikov, I. A.; Trifonova, E. A.; Putlyaev, E. V.; Mukhin, A. N.; Kalnov, S. L.; Balandina, M. V.; Tkachuk, A. P.; Gushchin, V. A.; Sarychev, A. K.; Lagarkov, A. N.; Rodionov, I. A.; Gabidullin, A. R.; Kurochkin, I. N. Non-labeled selective virus detection with novel SERS-active porous silver nanofilms fabricated by Electron Beam Physical Vapor Deposition. Sens. Actuators, B 2018, 257, 37-47.

(20) Premasiri, W. R.; Moir, D. T.; Klempner, M. S.; Krieger, N.; Jones, G.; Ziegler, L. D. Characterization of the Surface Enhanced Raman Scattering (SERS) of Bacteria. J. Phys. Chem. B 2005, 109, 312-320.

(21) Zeiri, L.; Bronk, B. V.; Shabtai, Y.; Czege, J.; Efrima, S. Silver metal induced surface enhanced Raman of bacteria. Colloids Surf., A 2002, 208, 357-362.

(22) Kahraman, M.; Yazici, M. M.; Sahin, F.; Bayrak, O. F.; Culha, M. Reproducible surface-enhanced Raman scattering spectra of bacteria on aggregated silver nanoparticles. Appl. Spectrosc. 2007, 61, 479-485.

(23) Popp, J.; Rosch, P.; Harz, M.; Schmitt, M.; Peschke, K.-D.; Ronneberger, O.; Burkhardt, H. Raman-Spectroscopy for a rapid identification of single microorganisms. Proc. SPIE 2006, 6180, No. 618024.

(24) Witkowska, E.; Szymborski, T.; Kamińska, A.; Waluk, J. Polymer mat prepared via Forcespinning as a SERS platform for immobilization and detection of bacteria from blood plasma. Mater. Sci. Eng. C 2017, 71, 345-350.

(25) Andrei, C. C.; Moraillon, A.; Larquet, E.; Potara, M.; Astilean, S.; Jakab, E.; Bouckaert, J.; Rosselle, L.; Skandrani, N.; Boukherroub, R.; Ozanam, F.; Szunerits, S.; Gouget-Laemmel, A. C. SERS characterization of aggregated and isolated bacteria deposited on silver-based substrates. Anal. Bioanal. Chem. 2021, 413, 1417-1428.

(26) Socransky, S. S.; Haffajee, A. D. Dental biofilms: difficult therapeutic targets. Periodontology 2000 2002, 28, 12-55. 
(27) Teles, R.; Teles, F.; Frias-Lopez, J.; Paster, B.; Haffajee, A. Lessons learned and unlearned in periodontal microbiology. Periodontology 2000 2013, 62, 95-162.

(28) Hajishengallis, G. Periodontitis: from microbial immune subversion to systemic inflammation. Nat. Rev. Immunol. 2015, 15, $30-44$.

(29) Genco, R. J.; Borgnakke, W. S. Risk factors for periodontal disease. Periodontology 2000 2013, 62, 59-94.

(30) Cullinan, M. P.; Seymour, G. J. Periodontal disease and systemic illness: will the evidence ever be enough? Periodontology 2000 2013, 62, 271-286.

(31) Potempa, J.; Mydel, P.; Koziel, J. The case for periodontitis in the pathogenesis of rheumatoid arthritis. Nat. Rev. Rheumatol. 2017, 13, 606-620.

(32) Michaud, D. S.; Fu, Z.; Shi, J.; Chung, M. Periodontal Disease, Tooth Loss, and Cancer Risk. Epidemiol. Rev. 2017, 39, 49-58.

(33) Dominy, S. S.; Lynch, C.; Ermini, F.; Benedyk, M.; Marczyk, A.; Konradi, A.; Nguyen, M.; Haditsch, U.; Raha, D.; Griffin, C.; Holsinger, L. J.; Arastu-Kapur, S.; Kaba, S.; Lee, A.; Ryder, M. I.; Potempa, B.; Mydel, P.; Hellvard, A.; Adamowicz, K.; Hasturk, H.; Walker, G. D.; Reynolds, E. C.; Faull, R. L. M.; Curtis, M. A.; Dragunow, M.; Potempa, J. Porphyromonas gingivalis in Alzheimer's disease brains: Evidence for disease causation and treatment with small-molecule inhibitors. Sci. Adv. 2019, 5, No. eaau3333.

(34) Rapala-Kozik, M.; Bras, G.; Chruscicka, B.; Karkowska-Kuleta, J.; Sroka, A.; Herwald, H.; Nguyen, K.-A.; Eick, S.; Potempa, J.; Kozik, A. Adsorption of components of the plasma kinin-forming system on the surface of Porphyromonas gingivalis involves gingipains as the major docking platforms. Infect. Immun. 2011, 79, 797-805.

(35) Naito, M.; Hirakawa, H.; Yamashita, A.; Ohara, N.; Shoji, M.; Yukitake, H.; Nakayama, K.; Toh, H.; Yoshimura, F.; Kuhara, S.; Hattori, M.; Hayashi, T.; Nakayama, K. Determination of the genome sequence of Porphyromonas gingivalis strain ATCC 33277 and genomic comparison with strain W83 revealed extensive genome rearrangements in P. gingivalis. DNA Res. 2008, 15, 215-225.

(36) Nelson, K. E.; Fleischmann, R. D.; DeBoy, R. T.; Paulsen, I. T.; Fouts, D. E.; Eisen, J. A.; Daugherty, S. C.; Dodson, R. J.; Durkin, A.; Gwinn, M.; Haft, D. H.; Kolonay, J. F.; Nelson, W. C.; Mason, T.; Tallon, L.; Gray, J.; Granger, D.; Tettelin, H.; Dong, H.; Galvin, J. L.; Duncan, M. J.; Dewhirst, F. E.; Fraser, C. M. Complete genome sequence of the oral pathogenic Bacterium Porphyromonas gingivalis strain W83. J. Bacteriol. 2003, 185, 5591-5601.

(37) Lasica, A. M.; Goulas, T.; Mizgalska, D.; Zhou, X.; de Diego, I.; Ksiazek, M.; Madej, M.; Guo, Y.; Guevara, T.; Nowak, M.; Potempa, B.; Goel, A.; Sztukowska, M.; Prabhakar, A. T.; Bzowska, M.; Widziolek, M.; Thøgersen, I. B.; Enghild, J. J.; Simonian, M.; Kulczyk, A. W.; Nguyen, K.-A.; Potempa, J.; Gomis-Rüth, F. X. Structural and functional probing of PorZ, an essential bacterial surface component of the type-IX secretion system of human oral-microbiomic Porphyromonas gingivalis. Sci. Rep. 2016, 6, No. 37708.

(38) Wang, Y.; Liu, A.; Chen, C. Genetic basis for conversion of rough-to-smooth colony morphology in Actinobacillus actinomycetemcomitans. Infect. Immun. 2005, 73, 3749-3753.

(39) Brogan, J. M.; Lally, E. T.; Poulsen, K.; Kilian, M.; Demuth, D. R. Regulation of Actinobacillus actinomycetemcomitans leukotoxin expression: analysis of the promoter regions of leukotoxic and minimally leukotoxic strains. Infect Immun. 1994, 62, 501-508.

(40) Berus, S.; Witkowska, E.; Niciński, K.; Sadowy, E.; Puzia, W.; Ronkiewicz, P.; Kamińska, A. Surface-enhanced Raman scattering as a discrimination method of Streptococcus spp. and alternative approach for identifying capsular types of $S$. pneumoniae isolates. Spectrochim. Acta, Part A 2020, 233, No. 118088.

(41) Nagano, K.; Hasegawa, Y.; Abiko, Y.; Yoshida, Y.; Murakami, Y.; Yoshimura, F. Porphyromonas gingivalis FimA fimbriae: fimbrial assembly by fimA alone in the fim gene cluster and differential antigenicity among fimA genotypes. PLoS One 2012, 7, No. e43722.

(42) Gorasia, D. G.; Veith, P. D.; Chen, D.; Seers, C. A.; Mitchell, H. A.; Chen, Y. Y.; Glew, M. D.; Dashper, S. G.; Reynolds, E. C. Porphyromonas gingivalis Type IX Secretion Substrates Are Cleaved and Modified by a Sortase-Like Mechanism. PLoS Pathog. 2015, 11, No. e1005152.

(43) Gorasia, D. G.; Veith, P. D.; Hanssen, E. G.; Glew, M. D.; Sato, K.; Yukitake, H.; Nakayama, K.; Reynolds, E. C. Structural Insights into the PorK and PorN Components of the Porphyromonas gingivalis Type IX Secretion System. PLoS Pathog. 2016, 12, No. e1005820.

(44) Lasica, A. M.; Ksiazek, M.; Madej, M.; Potempa, J. The Type IX Secretion System (T9SS): Highlights and Recent Insights into Its Structure and Function. Front. Cell. Infect. Microbiol. 2017, 7, No. 215.

(45) Emani, S.; Gunjiganur, G. V.; Mehta, D. S. Determination of the antibacterial activity of simvastatin against periodontal pathogens, Porphyromonas gingivalis and Aggregatibacter actinomycetemcomitans: An in vitro study. Contemp. Clin. Dent. 2014, 5, 377-382.

(46) Sharma, G.; Jeevanandam, P. A Facile Synthesis of Multifunctional Iron Oxide@Ag Core-Shell Nanoparticles and Their Catalytic Applications. Eur. J. Inorg. Chem. 2013, 2013, 6126-6136.

(47) Kubryk, P.; Niessner, R.; Ivleva, N. P. The origin of the band at around $730 \mathrm{~cm}^{-1}$ in the SERS spectra of bacteria: a stable isotope approach. Analyst 2016, 141, 2874-2878.

(48) Movasaghi, Z.; Rehman, S.; Rehman, I. U. Raman Spectroscopy of Biological Tissues. Appl. Spectrosc. Rev. 2007, 42, 493-541.

(49) Premasiri, W. R.; Lee, J. C.; Sauer-Budge, A.; Théberge, R.; Costello, C. E.; Ziegler, L. D. The biochemical origins of the surfaceenhanced Raman spectra of bacteria: a metabolomics profiling by SERS. Anal. Bioanal. Chem. 2016, 408, 4631-4647.

(50) Witkowska, E.; Korsak, D.; Kowalska, A.; Janeczek, A.; Kamińska, A. Strain-level typing and identification of bacteria - a novel approach for SERS active plasmonic nanostructures. Anal. Bioanal. Chem. 2018, 410, 5019-5031.

(51) Guzelian, A. A.; Sylvia, J. M.; Janni, J. A.; Clauson, S. L.; Spencer, K. M. SERS of whole-cell bacteria and trace levels of biological molecules. Proc. SPIE 2001, 4577, 182-192.

(52) Yang, D.; Zhou, H.; Dina, N. E.; Haisch, C. Portable bacteriacapturing chip for direct surface-enhanced Raman scattering identification of urinary tract infection pathogens. R. Soc. Open Sci. 2018, 5, No. 180955.

(53) Sjöberg, B.; Foley, S.; Cardey, B.; Enescu, M. An experimental and theoretical study of the amino acid side chain Raman bands in proteins. Spectrochim. Acta, Part A 2014, 128, 300-311.

(54) Chen, Y.; Premasiri, W. R.; Ziegler, L. D. Surface enhanced Raman spectroscopy of Chlamydia trachomatis and Neisseria gonorrhoeae for diagnostics, and extra-cellular metabolomics and biochemical monitoring. Sci. Rep. 2018, 8, No. 5163.

(55) Demirel, M. C.; Kao, P.; Malvadkar, N.; Wang, H.; Gong, X.; Poss, M.; Allara, D. L. Bio-organism sensing via surface enhanced Raman spectroscopy on controlled metal/polymer nanostructured substrates. Biointerphases 2009, 4, 35-41.

(56) Luna-Pineda, T.; Soto-Feliciano, K.; De La Cruz-Montoya, E.; Pacheco Londoño, L. C.; Ríos-Velázquez, C.; Hernández-Rivera, S. P. Spectroscopic characterization of biological agents using FTIR, normal Raman and surface-enhanced Raman spectroscopies. Proc. SPIE 2007, 6554, No. 65540K.

(57) Sroka, A.; Sztukowska, M.; Potempa, J.; Travis, J.; Genco, C. A. Degradation of host heme proteins by lysine- and arginine-specific cysteine proteinases (gingipains) of Porphyromonas gingivalis. J. Bacteriol. 2001, 183, 5609-5616.

(58) Witkowska, E.; Nicinski, K.; Korsak, D.; Szymborski, T.; Kaminska, A. Sources of variability in SERS spectra of bacteria: comprehensive analysis of interactions between selected bacteria and plasmonic nanostructures. Anal. Bioanal. Chem. 2019, 411, 20012017.

(59) Liu, T. Y.; Tsai, K. T.; Wang, H. H.; Chen, Y.; Chen, Y. H.; Chao, Y. C.; Chang, H. H.; Lin, C. H.; Wang, J. K.; Wang, Y. L. Functionalized arrays of Raman-enhancing nanoparticles for capture and culture-free analysis of bacteria in human blood. Nat. Commun. 2011, 2, No. 538.

(60) Stamplecoskie, K. G.; Scaiano, J. C.; Tiwari, V. S.; Anis, H. Optimal Size of Silver Nanoparticles for Surface-Enhanced Raman Spectroscopy. J. Phys. Chem. C 2011, 115, 1403-1409. 
(61) Haraszthy, V. I.; Sreenivasan, P. K. Microbiological and clinical effects of an oral hygiene regimen. Contemp. Clin. Trials Commun. 2017, 8, 85-89.

(62) Salako, N. O.; Rotimi, V. O.; Preeta, R.; Khodakhast, F. The bacteriology of the supragingival plaque of child dental patients in Kuwait. Med. Princ. Pract. 2004, 13, 191-195.

(63) Sawosz, E.; Chwalibog, A.; Mitura, K.; Mitura, S.; Szeliga, J.; Niemiec, T.; Rupiewicz, M.; Grodzik, M.; Sokołowska, A. Visualisation of morphological interaction of diamond and silver nanoparticles with Salmonella enteritidis and Listeria monocytogenes. J. Nanosci. Nanotechnol. 2011, 11, 7635-7641.

(64) Muro, C. K.; de Souza Fernandes, L.; Lednev, I. K. Sex Determination Based on Raman Spectroscopy of Saliva Traces for Forensic Purposes. Anal. Chem. 2016, 88, 12489-12493.

(65) Moisoiu, V.; Badarinza, M.; Stefancu, A.; Iancu, S. D.; Serban, O.; Leopold, N.; Fodor, D. Combining surface-enhanced Raman scattering (SERS) of saliva and two-dimensional shear wave elastography (2D-SWE) of the parotid glands in the diagnosis of Sjögren's syndrome. Spectrochim. Acta, Part A 2020, 235, No. 118267.

\section{NOTE ADDED AFTER ASAP PUBLICATION}

This paper was published ASAP on April 1, 2021, with italics missing from several occurrences of Streptococcus spp. The corrected version was reposted on April 6, 2021. 